\title{
How Research on Human Progeroid and Antigeroid Syndromes Can Contribute to the Longevity Dividend Initiative
}

\author{
Fuki M. Hisama ${ }^{1,3}$, Junko Oshima ${ }^{2,3,4}$, and George M. Martin ${ }^{2,3}$ \\ ${ }^{1}$ Division of Medical Genetics, Department of Medicine, University of Washington School of Medicine, \\ Seattle, Washington 98195 \\ ${ }^{2}$ Department of Pathology, University of Washington School of Medicine, Seattle, Washington 98195 \\ ${ }^{3}$ International Registry of Werner Syndrome, University of Washington School of Medicine, Seattle, \\ Washington 98195 \\ ${ }^{4}$ Department of Medicine, Chiba University, Chiba 260-8670, Japan \\ Correspondence: gmmartin@uw.edu
}

\begin{abstract}
Although translational applications derived from research on basic mechanisms of aging are likely to enhance health spans and life spans for most of us (the longevity dividend), there will remain subsets of individuals with special vulnerabilities. Medical genetics is a discipline that describes such "private" patterns of aging and can reveal underlying mechanisms, many of which support genomic instability as a major mechanism of aging. We review examples of three classes of informative disorders: "segmental progeroid syndromes" (those that appear to accelerate multiple features of aging), "unimodal progeroid syndromes" (those that impact on a single disorder of aging), and "unimodal antigeroid syndromes," variants that provide enhanced protection against specific disorders of aging; we urge our colleagues to expand our meager research efforts on the latter, including ancillary somatic cell genetic approaches.
\end{abstract}

\begin{abstract}
A successful translation of the "longevity divAidend" concept will require a fuller understanding of the fundamental mechanisms of intrinsic and extrinsic mechanisms of biological aging. In this review, we summarize what could be characterized as a medical genetics approach to the discovery of at least a subset of such mechanisms. That approach takes advantage of what might be called "experiments of nature"-mutations whose phenotypes appear to accelerate the ages of onset and the rates of progression of aging and diseases of aging (i.e., the "pathobiology of aging"). These can be clas-
\end{abstract}

sified in two broad subtypes-those that mainly impact a single predominant phenotype associated with aging, "unimodal progeroid syndromes" (Martin 1982; Martin 2005) and those that impact multiple phenotypes, "segmental progeroid syndromes" (Table 1) (Martin 1978; Martin 2005). The latter class of syndromes has been a major focus of our research and has in fact revealed a fundamental underlying general mechanism of biological aginggenomic instability. We shall also briefly review the status of research on examples of "unimodal progeroid syndromes." Although these studies

Editors: S. Jay Olshansky, George M. Martin, and James L. Kirkland

Additional Perspectives on Aging available at www.perspectivesinmedicine.org

Copyright (C) 2016 Cold Spring Harbor Laboratory Press; all rights reserved; doi: 10.1101/cshperspect.a025882

Cite this article as Cold Spring Harb Perspect Med 2016;6:a025882 
F.M. Hisama et al.
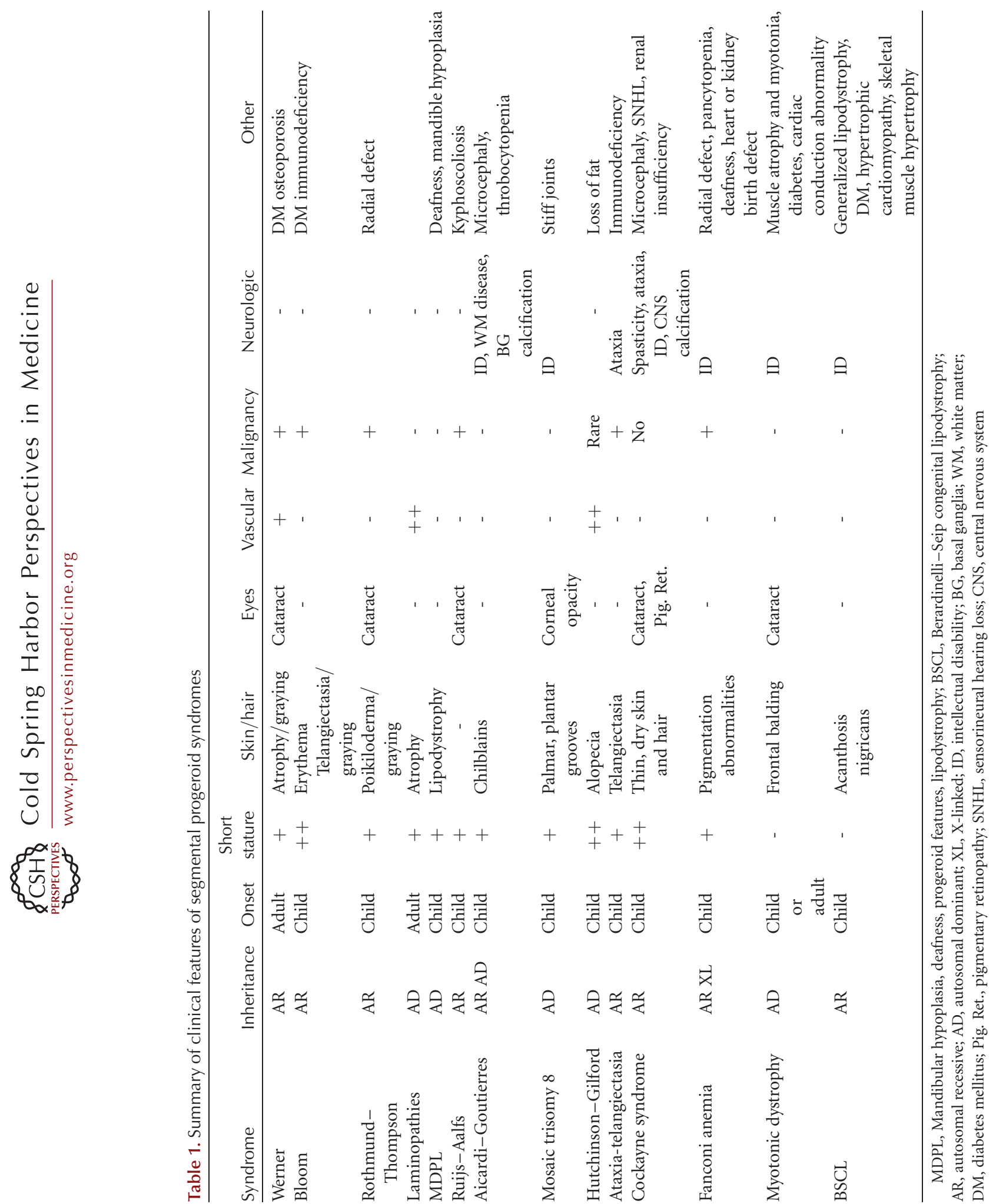
are much less well developed, they are of potentially much greater relevance to the longevity dividend initiative. Given the biochemical genetic uniqueness of individual members of our species, one can anticipate that, despite major benefits from interventions that slow the intrinsic rates of aging, thus postponing multiple diseases of aging, many or perhaps most of us may still be handicapped by one or more "Achilles heels" of susceptibility to specific age-related disorders - susceptibilities that are functions of both constitutional genetic vulnerabilities, their interactions with environment, as well as a range of genetic and epigenetic stochastic events (Martin 2012). Although the disorders we are reviewing result from mutations with very large effects, we still have a great deal to learn about less penetrant mutations, polymorphic variants, and polygenic contributions to what may present as more subtle "Achilles heels," particularly given deleterious interactions with environmental agents. The same may be true for heterozygous carriers of autosomal recessive disorders. Our criteria for the definitions of segmental and unimodal progeroid syndromes have therefore been biased in favor of ascertainments of strongly expressed phenotypes consistent with accelerated rates of biological aging in one or more spheres of pathophysiology. There is much work to be performed by medical geneticists to enhance our understanding of more subtle phenotypic outliers.

This review also makes a plea for a new medical genetics research initiative. By definition, our clinics only enroll individuals and families in which the mutational experiments of nature lead to diminished structure and function. We will argue that it is time to also turn our attention to the discovery of alleles that provide remarkable degrees of enhanced structure and function for a range of relevant physiologies. Although there are colleagues engaged in the genetic analysis of human subjects with exceptionally long health spans and life spans, as reviewed by Milman and Barzilai (2015), the genetic analysis of individuals displaying exceptionally robust retention of function in specific physiological domains (cardiovascular, pulmonary, renal, skeletal muscular, hematopoietic, etc.) has been comparatively neglected, perhaps with the exception of studies that have examined the genetic basis of resistance to dementias of the Alzheimer type (DATs). We shall refer to such yet-to-be-discovered medical genetic entities as "unimodal antigeroid syndromes," in keeping with the nomenclature of "antigeroid alleles" (Finch and Kirkwood 2000; Martin and Oshima 2000).

\section{EXAMPLES OF SEGMENTAL PROGEROID SYNDROMES}

\section{Werner Syndrome-The Prototypic Segmental Progeroid Syndrome}

Werner syndrome (WS) is perhaps the best example of segmental progeroid syndromes as the affected individuals undergo multiple features of accelerated aging (Fig. 1A) (Oshima et al. 2014). It is one of the few examples of adultonset progeroid syndromes in which aged-appearances and common age-related disorders begin to manifest in the third decade of life. Short stature, which starts in the early teens, is often the first recognized sign. Typically, patients develop skin atrophy with loss of subcutaneous fat and graying and loss of hair in their 20s, bilateral cataracts in their late 20s or early 30s, hypogonadism, and, subsequently, a series of age-related diseases including type 2 diabetes mellitus, osteoporosis, atherosclerosis, and a variety of malignancies. WS patients have a disproportionally higher incidence of sarcomas, however (Goto et al. 1996), suggesting the importance of genomic instabilities of mesenchymal cells. Severe ulcerations occur in the lower extremities; these often lead to amputations. They are primarily related to a form of arteriosclerosis known as medial calcinosis. Interestingly, DATs are not well-recognized features of WS. The most recent data indicate a median age of death of $54 \mathrm{yr}$, usually caused by either cancer or myocardial infarction (Oshima et al. 2014).

WS is a rare autosomal recessive disorder caused by null mutations at the WRN locus, a member of the RecQ family of helicases. It encodes a nuclear protein with a $3^{\prime} \rightarrow 5^{\prime}$ exonuclease domain in its amino-terminal region, a 
F.M. Hisama et al.
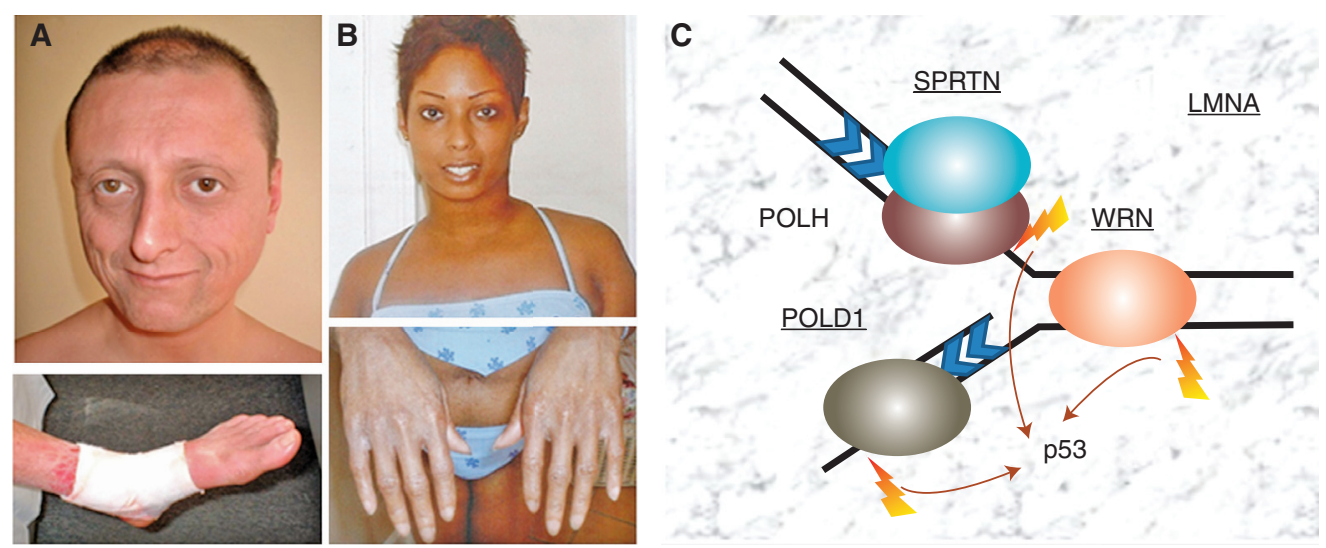

Figure 1. Examples of progeroid patients and selected causal genes for segmental progeroid syndromes. (A) A 35yr-old Italian Caucasian male, registry \#ROMA1010, with a homozygous WRN mutation, c.867_874delAGAAAATC (p.Glu290fs) (Friedrich et al. 2010). He had a characteristic ankle ulcer (with bandage). (B) A 23-yr-old African-American Caucasian female, registry \#ATLAN1010 with a heterozygous LMNA mutation, c.398G $>$ T ( p.Arg133Leu) (Chen et al. 2003). Atrophic skin of hands is shown. (C) Examples of major causal genes of segmental progeroid syndromes associated with DNA damage repair and response. Mutated loci so far identified among cases of atypical Werner syndrome (WS) within the International Registry of WS are underlined.

$3^{\prime} \rightarrow 5^{\prime}$ helicase in its central region, and a nuclear localization signal in its carboxy-terminal region (Croteau et al. 2014). The majority of disease mutations are nonsense mutations and small indels that truncate nuclear localization signals and/or cause nonsense-mediated RNA decay (Friedrich et al. 2010). Genomic rearrangements with or without involvement of neighboring loci have also been identified. With the advancement of next-generation DNA sequencing, WRN heterozygous disease mutations have been identified in association with at least one other known genetic disorder (see below, Aicardi-Goutieres syndrome) (Lessel et al. 2014a).

mTOR inhibitors have been shown to improve cellular growth and to reduce the accumulation of DNA damage (Talaei et al. 2013; Saha et al. 2014). Astaxanthin, an antioxidant, has shown improvement of fatty deposition in the liver of one case (Takemoto et al. 2015). WSinduced pluripotent stem cells have been generated in two independent laboratories and should be very useful for further research on the phenotypic alterations in a range of somatic cells (Cheung et al. 2014; Shimamoto et al. 2014).
More research is needed on the potential impacts of polymorphic variants and of potential deleterious interactions in heterozygotic carriers with genotoxic environmental agents (Ogburn et al. 1997; Blank et al. 2004). Several population studies have already linked the p.Leu1075Phe polymorphism with longevity, where a minor allele was associated with decreased longevity (Sebastiani et al. 2012).

\section{Other RecQ Helicase Disorders}

\section{Bloom Syndrome}

Bloom syndrome is a rare, autosomal recessive disorder recognized by a dermatologist, Dr. David Bloom who described three children with short stature and a sun-sensitive telangiectatic facial erythema (Bloom 1954). Additional clinical features include prenatal growth restriction, hypo- or hyperpigmentation elsewhere on the body, an immunodeficiency, and the following features that overlap with common features of aging: a paucity of subcutaneous fat, reduced male and female fertility, and increased risk of diabetes and cancers, particularly types of leukemias, non-Hodgkin's lymphomas, and carcinomas seen in the general population 
(German et al. 1984; Kaneko and Kondo 2004). Bloom syndrome is more frequent in the Ashkenazi Jewish population owing to a founder effect.

Bloom syndrome is caused by mutations in one of the five human RecQ helicase genesnamely, BLM, also known as RECQL3. Biallelic mutations result in detectable chromosomal aberrations, including abnormal nuclei in interphase cells and excessive chromosome breaks, gaps, translocations, and quadriradials. In cells treated with bromodeoxyuridine (BrdU), the frequency of sister chromatid exchanges in cells from Bloom syndrome subjects is increased 10fold compared with cells from controls, and is considered diagnostic (Chaganti et al. 1974). Thus, BLM functions to suppress hyperrecombination, and its absence results in genomic instability.

$B L M$ is the only gene that, when mutated, causes Bloom syndrome. The majority of mutations result in loss-of-function caused by premature truncating, frameshift, splice-site or deletion mutations. The few causative missense substitutions so far reported are predicted to affect its helicase activity.

Expression of BLM increases in the $S$ phase and $G_{2} / M$ phase, and is localized to promyelocytic nuclear (PML) bodies and telomeres in the nucleus. BLM is rapidly recruited to sites of DNA damage, and can unwind forked double-stranded DNA (dsDNA) and anneal singlestranded DNA (ssDNA). In vitro, BLM stimulates DNA end resection, an exonucleiolytic process that generates ssDNA tails at a DNA double-strand break (DSB). BLM has been found to interact in vitro with replication protein A (RPA), which increases the efficiency of BLM for unwinding DNA substrates. Through direct and indirect protein interactions, BLM functions in DNA repair, recombination, replication, and thereby contributes to the maintenance of genomic stability (Wu et al. 2001; Machwe et al. 2011).

\section{Rothmund-Thomson Syndrome}

Rothmund-Thomson syndrome (RTS) was reported in 1887 by a German ophthalmologist,
August Rothmund, and in 1936 by a British dermatologist, Sidney Thomson. Most patients develop erythematous plaques on the cheeks, which spread to the forehead, ears, and neck. Telangiectasias similar to Bloom syndrome are common. Later, poikiloderma appears, resulting in dry, atrophic skin. The skin shows a marbleized appearance of hyperpigmentation and hypopigmentation in sun-exposed areas. Variable features include short stature, graying hair with sparse eyebrows/eyelashes, childhood cataracts, small saddle-shaped nose, and dystrophic teeth and nails (Vennos and James 1995). RTS patients are prone to develop osteosarcoma and squamous cell carcinoma (Drouin et al. 1993). Features that overlap with aging in the general population include graying hair, cataracts, and cancer risk. There is overlap among the three RecQ helicase-associated human diseases in terms of autosomal recessive inheritance, short stature, early onset of cataracts, skin changes, and increased risk of malignancy. In contrast to the other two diseases associated with RecQ helicase dysfunction (WS and Bloom syndrome), RTS patients do not have increased risk of type 2 diabetes mellitus. Hypoplastic thumbs are another occasional distinguishing feature.

In 1999, mutations were identified in RECQL4 in a subset of patients with RTS (Kitao et al. 1999). In contrast to Bloom syndrome and WS, in which $>85 \%$ of patients have mutations in the designated member of the RecQ helicase family, mutations in RECQL4 can be identified in approximately two-thirds of RTS cases (Wang et al. 2001). No other germline mutations causing RTS have been identified to date. After the identification of RECQL4 mutations as the cause of RTS, two other disorders with radial defects and short stature were found to be caused in some cases by RECQL4 mutations: the Baller-Gerold syndrome and RAPADILINO (Siitonen et al. 2003; Van Maldergem et al. 2006).

Although the RECQL4 helicase has the helicase domain common to all members of the RecQ family, it lacks the exonuclease domain of $W R N$, and lacks the clear nuclear localization signal of WRN and BLM. Nevertheless, by fluorescence immunostaining, RECQL4 is localized 
F.M. Hisama et al.

mainly in the nucleoplasm, but also exists in the nucleolus. RECQL4 participates in nonhomologous end-joining. It is also essential for transport of $\mathrm{p} 53$ to mitochondria, where they potentiate the activity of polymerase $\gamma$ (De et al. 2012; Gupta et al. 2014). In contrast to WRN knockout mice, which are born without an apparent phenotype, the RECQL4 knockout results in early murine embryonic lethality; however, a mouse model with a deletion of exon 13 has features of RTS (Hoki et al. 2003; Lord et al. 2014). These results underscore differences in the biological functions of the RecQ helicases. The fact that these proteins are unable to compensate for one another's functions further underscores their special differentiations.

\section{Atypical Werner Syndrome}

\section{Laminopathies}

After the identification of mutations in WRN in subjects with WS, it became clear that, although most affected individuals carried biallelic mutations, often identical by descent, $\sim 15 \%$ of individuals thought to have WS on clinical grounds, had no detectible WRN mutations in coding domains and had normal levels and electrophoretic mobilities of WRN protein by Western blots.

Operationally, we classified these individuals as having "atypical WS." These subjects often did not meet clinical criteria for definite or even probable WS (www.wernersyndrome.org). For example, the patient might have prematurely gray hair and an aged appearance, but might lack bilateral cataracts, the most penetrant feature of classical WS. One of the first candidate genes examined in patients with atypical WS was the lamin A/C gene (LMNA), dominant mutations at which had recently been discovered to be the cause of childhood-onset progeria, also known as the Hutchinson-Gilford progeria syndrome (HGPS). In four out of 26 (15\%) of atypical WS subjects within the International Registry of WS, a deleterious LMNA mutation was found, but the mutations differed from the classic mutation of HGPS (Fig 1B) (Chen et al. 2003). Two families studied in more detail were found to have short stature, nonprogeroid appearance in childhood, but with the onset of progeroid features and the appearance of severe cardiovascular disease in adulthood, in sharp contrast to the much earlier onsets seen in HGPS. Each subject had an LMNA mutation that was associated with the production of the pathognomonic "progerin" protein of HGPS, a novel isoform, which, in HGPS, is the result of a 50-amino-acid deletion. The levels of progerin in these atypical cases, however, were substantially less than what is observed in HGPS (Hisama et al. 2011). The relevance of these observations for our understanding of the pathogenesis of atherosclerosis is highlighted by observations of increasing amounts of progerin in the media and adventitia of arterial walls and in atherosclerotic plaques as during human aging (Olive et al. 2010). The unusual degree of adventitial fibrosis in the atherosclerotic arteries of HGPS patients, however, is a caveat regarding the relevance of this disorder for the usual pathogenetic mechanisms of the disease (Olive et al. 2010).

LMNA encodes intermediate filament proteins of the nuclear lamina and nucleoplasmic structures, which are tightly associated with chromatin. Mature lamin A is produced by a series of posttranslational modification steps including farnesylation, methylation, and cleavage of 18 residues of the precursor protein, termed prelamin. Mutations in zmpste24, a metalloproteinase, which acts in the cleavage of prelamin, cause a neonatal progeroid restrictive dermopathy. LMNA is a "gene with many faces"; it causes more than ten distinct human diseases. These can be grouped into those with a neuromuscular phenotype (inherited recessive peripheral neuropathy, Emery-Dreifuss, and other muscular dystrophies), a phenotype of dilated cardiomyopathy with cardiac conduction disease, and progeroid or lipodystrophy disorders (atypical WS, mandibuloacral dysplasia, or familial partial lipodystrophy type 2) (reviewed in Capell and Collins 2006).

\section{MDPL Syndrome}

Germline mutations of the POLD1 gene can cause an autosomal dominant multisystem 
disorder known as the MDPL syndrome (mandibular hypoplasia, deafness, progeroid features, lipodystrophy) (Weedon et al. 2013). MDPL patients begin to develop prominent loss of subcutaneous fat, a characteristic facial appearance, metabolic abnormalities, including diabetes mellitus, and progeroid features usually during the first to second decades of life. Sensorineural deafness is seen in most, but not all cases. Undescended testes and hypogonadism have been reported in males but females may be fertile.

The POLD1 gene encodes one of the main replicative polymerases, which contains an intrinsic exonuclease domain and interacts with WRN protein (Kamath-Loeb et al. 2012). Its primary role is in lagging strand synthesis and also functions as a translesion synthesis (TLS) polymerase. Unlike $P O L H$, which catalyzes the TLS of the leading strand, POLD1 functions in postreplication repair of the lagging strand during DNA replication. Most heterozygous POLD1 mutations found in MDPL patients are a deletion (p.S605del) within the polymerase domain. A single missense mutation located in its exonuclease domain has also been identified (Weedon et al. 2013; Pelosini et al. 2014). Several germline mutations in POLD1 exonuclease domains are also known to predispose to cancers, particularly familial colorectal cancers (Palles et al. 2013).

\section{Ruijs-Aalfs Syndrome}

The Ruijs-Aalfs syndrome (RAS) is an early onset genomic instability syndrome characterized by developmental retardation, skeletal abnormalities, and a progeroid appearance (Ruijs et al. 2003). It is a rare autosomal recessive disorder caused by homozygous or compound heterozygous mutations in SPRTN (SprT-like amino-terminal domain). RAS patients are unusually sensitive to a specific type of malignancy, hepatocarcinoma, which can develop as early as the late teens (Lessel et al. 2014b).

SPRTN was originally identified as an interacting protein of ubiquitinated proliferating cell nuclear antigen (PCNA), a protein that is recruited to the sites of UV-induced DNA damage (Centore et al. 2012). The SPRTN associates with a TLS polymerase $\eta$ (eta; encoded by $P O L H)$ on UV damage to stabilize the repair complex and enhance TLS. Cells carrying SPRTN mutations show hypersensitivities to certain genotoxic agents, consistent with the role of SPRTN in TLS and in $\mathrm{G}_{2} / \mathrm{M}$-checkpoint regulation (Lessel et al. 2014b).

\section{Aicardi-Goutieres Syndrome}

The Aicardi-Goutieres syndrome (AGS) is a progressive neurological disorder characterized by early onset encephalopathy, intellectual disability, and intracranial calcification involving the basal ganglia (Stephenson 2008). Hepatomegaly, thrombocytopenia, and chilblains are frequent. AGS is genetically heterogeneous. Causative genes include TREX1, which encodes a $3^{\prime} \rightarrow 5^{\prime}$ TREX1 exonuclease, components of the RNASEH2 endonuclease complex (RNASEH2B, RNASEH2C, RNASEH2D) and $S A M H D 1$, which encodes a deoxynucleotide triphosphohydrolase (Stephenson 2008; Rice et al. 2009). The SAMHD1 protein regulates intracellular pools of deoxynucleotide triphosphates (dNTPs) and also plays a role in regulation of cell proliferation and survival, and part of the response to DNA damage (Clifford et al. 2013).

One of the puzzling features of AGS is its pronounced phenotypic variability, which is quite unusual for autosomal recessive conditions. In particular, phenotypes associated with SAMHD1 mutations range from "classical" presentations to those with mild intellectual disability or a nonspecific chronic inflammatory skin condition (Rice et al. 2009; Dale et al. 2010). A Turkish pedigree with a homozygous AGS mutation was identified among subjects enrolled in the International Registry of WS as having atypical WS (Lessel et al. 2014a). The patient also carried a heterozygous WRN mutation, raising the possibility that heterozygosity at the WRN locus may modify AGS phenotypes. Future research should explore the role of WRN heterozygosity in the modulation of other genomic instability syndromes. 
F.M. Hisama et al.

\section{Mosaic Trisomy 8}

Trisomy 8 mosaicism is seen in individuals whose complement is mosaic for chromosome 8 , meaning they have a chromosomally normal cell line, in addition to a cell line that is trisomic for chromosome 8 . Full (nonmosaic) trisomy 8 is generally considered a lethal condition.

Common features in mosaic trisomy 8 patients include mild to moderate intellectual disability, agenesis of the corpus callosum, corneal opacities, strabismus, low set ears, a broad bulbous nose, congenital palate defect, congenital heart defect, hydronephrosis, cryptorchidism, and stiff joints. Deep vertical grooves of the palms and soles of the feet are also characteristic (Fineman et al. 1975). The features of mosaic trisomy 8, which overlap with aging in the normal population include cataracts and joint stiffness.

A remarkable feature of mosaic trisomy 8 is the variability in the clinical manifestations. The mechanisms that underlie this variability are not fully understood but must be determined in large degree by the extent and patterns of mosaicism, including tissue-specific effects. An online support group for rare chromosomal disorders (www.rarechromo.org) reports 23 adult members with trisomy 8 mosaicism. These subjects show a wide range of degrees of intellectual disability, from none (one is a college professor) to those requiring assistance for activities of daily living (Baidas et al. 2004).

One subject referred to the International Registry of WS was found to have trisomy 8 mosaicism in cultured fibroblast cells (Oshima and Hisama 2014). The WRN gene is located on chromosome $8 \mathrm{p} 12$, which means that individuals mosaic for trisomy 8 are predicted to have an additional functional copy of WRN. In contrast to the prototypic biallelic loss-of-function mutations that cause WS, whether and how trisomy for WRN contributes to the features of trisomy 8 is not yet known.

\section{Hutchinson-Gilford Progeria Syndrome}

The two segmental progeroid disorders with the most striking features of accelerated aging are
WS (also termed adult-onset progeria) and the Hutchinson-Gilford progeria syndrome (HGPS, also termed childhood-onset progeria). Infants born with HGPS are normal appearing at birth but experience severe growth restriction in the first year of life. The affected children are always short and thin, and reach a final weight of $11-18 \mathrm{~kg}(25-40 \mathrm{lb})$ as teenagers (Gordon et al. 1993).

HGPS patients have a characteristic facial appearance, which is distinctive and pathognomonic to the informed clinician. This constellation of features include a bald head with loss of eyelashes and eyebrows, prominent eyes, beaked nose, and small jaw. Widespread loss of "baby fat" leads to prominent veins and an "aged" appearance to the skin. Additional features include acro-osteolysis, stiff finger joints, enlarged elbow and knee joints, coxa valga, aseptic necrosis of the head of the femur, as well as medical complications from severe atherosclerosis, with most deaths historically occurring around age $12 \mathrm{yr}$, with the causes of death largely by myocardial infarctions, strokes, or congestive heart failure. Although loss of hair, loss of subcutaneous fat and cardiovascular disease are common in the normal aging population, other common feature of aging, including tumors, cataracts, diabetes, and hyperlipidemia are not usually present in HGPS (Merideth et al. 2008). The paucity of at least some of these features (notably cancer) may simply be related to the short life spans of these patients.

Two major challenges to the identification of the genetic basis for HGPS were (1) its rarity, with a prevalence of about one in eight million, and (2) the fact that it nearly always occurs as a sporadic disorder, therefore creating difficulties for traditional genetic methodologies such as positional cloning. Cytogenetic abnormalities, however, localized the candidate region to chromosome 1q, and the cause of HGPS was found to be a de novo recurrent silent substitution in exon 11 of lamin A/C (LMNA), which activates a cryptic splice site, resulting in the production of a protein with a deletion of $\sim 50$ amino acids at the carboxyl terminus (Eriksson et al. 2003). This truncated protein (termed progerin) causes a dramatic change in the shape of the nuclear 
envelope, thickening of the nuclear lamina, and loss of peripheral heterochromatin. Progerin also accumulates in fibroblasts and coronary arteries in an age-dependent fashion in the normal population (McClintock et al. 2007; Olive et al. 2010).

In addition to the alterations of the nucleus, there is strong evidence that the cellular phenotype of HGPS includes genomic instability. In HGPS fibroblasts, there is a delayed checkpoint response, and defective response to DNA damage (Liu et al. 2005, 2006). Furthermore, A-type lamins bind to mammalian telomeres in vivo, and play a role in telomere maintaining telomere length, structure, and function. $\mathrm{LMNA}^{-/-} \mathrm{fi}-$ broblasts show aneuploidy, increased frequency of chromosome breaks, and defects in nonhomologous end-joining of dysfunctional telomeres (Andres and Gonzalez 2009).

This raises the question, then, of why cancers (a classic feature of many chromosomal instability syndromes) are not part of the usual picture of HGPS. Osteosarcoma at age 9 yr was reported in one girl with a missense variant in LMNA that causes a later onset of HGPS, and is compatible with survival into the fifth decade. It may be, as the investigators suggest, that in most patients with HGPS the severe atherosclerotic disease with death in the second decade masks an increased cancer risk, which would be evident at an older age (Shalev et al. 2007).

HGPS is a good example of the productive synergy between families affected by rare disorders and scientists interested in investigating such disorders. The family of an affected child founded the Progeria Research Foundation with a mission to discover treatments and, potentially, cures of HGPS and related disorders of aging (www.progeriaresearch.org). Despite HGPS being one of the more recent gene mutations discovered to be the basis of a segmental progeroid syndrome, promising results of a clinical treatment trial of farnesylation inhibitors were published a mere 11 yr later (Gordon et al. 2014).

\section{Ataxia Telangiectasia}

Ataxia telangiectasia (AT) is a member of the group of rare, human diseases that are charac- terized by marked chromosomal instability, increased cancer risk and progeroid features. AT patients are normal at birth, but typically develop difficulty walking in the second year of life. They gradually develop neurological impairments such as ataxia, ocular apraxia, dysarthric speech, and choreoathetoid movements. In addition, they have humeral and cellular immune defects, with frequent sinus or ear infections. The lifetime cancer risk for AT patients reaches $30 \%-40 \%$, with the most common childhood malignancies being acute lymphocytic leukemia, non-Hodgkin and Hodgkin lymphomas. The most common adult malignancies are T-cell leukemias and solid tumors (Woods and Taylor 1992). The progeroid features in AT homozygotes include the increased risk of cancer, telangiectasias, graying hair, skin atrophy, and pigmentation changes. AT individuals have reduced fertility from abrupt apoptosis of germ cells in response to a defect in meiotic recombination. Heterozygous female ATM carriers are at increased risk of breast cancer (Thompson et al. 2005).

Chromosomal instability is evident in lymphoid and nonlymphoid cells from AT patients. Their frequent, spontaneous in vivo chromosomal aberrations include DSBs and telomere abnormalities (Meyn 1993). Cultured cells from AT patients are exquisitely sensitive to the cytotoxic effects of ionizing radiation.

The ATM gene was identified by positional cloning in 1995 . The majority (85\%) of mutations consists of nonsense and splice site mutations that produce prematurely truncated proteins (Savitsky et al. 1995). AT deficient cells show defects in multiple cell cycle checkpoints and in the signaling pathways that activate a network of responses to DNA DSBs.

\section{Cockayne Syndrome}

Two major forms of arteriosclerosis (atherosclerosis and arteriolosclerosis), hypertension, agerelated renal pathology, presbycusis, cognitive decline, and the loss of subcutaneous adipose tissue are among the diverse phenotypes that permit the characterization of the Cockayne syndrome as a segmental progeroid syndrome 
F.M. Hisama et al.

(Laugel 2013). Mutations in at least five loci have been associated with this syndrome, CSA, $C S B, X P B, X P D$, and $X P G$, thus documenting pathogenetic overlaps with Xeroderma pigmentosa (Jaarsma et al. 2013). The XPB locus has been characterized as a $3^{\prime} \rightarrow 5^{\prime}$ DNA helicase, a member of the "super family 2" (SF2) group of helicases and a subunit of the transcription factor complex TFIIH, which functions both in transcription and DNA repair (Fan and DuPrez 2015).

About two-thirds of Cockayne patients have mutations at CSB and approximately one-third at the CSA locus (Laugel 2013). The underlying pathogenesis involves defects in transcriptioncoupled excision repair of DNA (Marteijn et al. 2014). Oxidative stress and mitochondrial dysfunction have also been associated with the Cockayne syndrome and have been shown to be related to depletion of the catalytic subunit of DNA polymerase $\gamma$, the enzyme responsible for replicating mitochondrial DNA. That depletion was associated with the accumulation of a serine protease; of great potential therapeutic significance, the phenotype could be reversed by a serine protease inhibitor (Chatre et al. 2015).

\section{Fanconi Anemia}

An interest in Fanconi anemia as a segmental progeroid syndrome is immediately suggested by its earlier designation as a "pancytopenia" (Neveling et al. 2009). In addition to multiple and variably expressed developmental phenotypes, one observes many phenotypes that can be interpreted as evidence of premature aging, including endocrine abnormalities, gonadal failure, sarcopenia, osteoporosis, increased susceptibility to infectious agents, and progeroid features of skin (Neveling et al. 2009). Additional relevant observations have included nuclear aberrations and diminished replication of cultured fibroblasts (Willingale-Theune et al. 1989), hypersensitivity to oxidative stress (Liebetrau et al. 1997), mitochondrial damage (Pagano et al. 2014), and preneoplastic lesions such as leukoplakias of the oral cavity (Grein Cavalcanti et al. 2015) and early myelodysplasias
(Quentin et al. 2011). It has also been described as "a highly penetrant cancer susceptibility syndrome” (Auerbach 2009). Were it not for early deaths from bone marrow failure, infectious diseases ad highly malignant neoplasms, one would likely observe a much larger burden of cancers commonly seen within the general aging population.

Current evidence points to some 16 distinct genetic loci, mutations of which are associated with the clinical diagnoses of Fanconi anemia (Walden and Deans 2014). Both autosomal recessive and X-linked modes of inheritance have been implicated (Oostra et al. 2012). These loci all appear to be involved in a complex hierarchy of gene actions that focus on the repair of DNA cross-links, a ubiquitin ligase complex for two key substrates and downstream proteins involved in nuclease-dependent and recombinational functions (Walden and Deans 2014). DNA cross-linking agents have been associated with endogenous and exogenous sources of aldehydes. These notably include derivations from the peroxidation of lipids, one of a number of postulated major elements of the oxidative damage theory of aging (Schottker et al. 2015).

\section{Myotonic Dystrophy}

Although the name "myotonic dystrophy" (MD) suggests a unimodal progeroid syndrome-specifically, as a model for age-related sarcopenia (Malatesta et al. 2014), there is a much broader range of phenotypes. An expert on MD, Peter S. Harper, has stated that "... anything that can go wrong does go wrong in myotonic dystrophy” (Harper et al. 2001)! This is the case for both type $1 \mathrm{MD}$ (also known as Steinart's disease) and a much milder form known as type $2 \mathrm{MD}$. These phenotypes (Meola and Cardani 2015) include myocardial conduction defects, insulin resistance, ocular cataracts, male hypogonadism and frontal baldness, respiratory failure, and a range of neurological and behavioral disorders, including sleep disorders (Axford and Pearson 2013; Laberge et al. 2013). Both types of MD are inherited as autosomal dominants. Although different genetic 
Human Progeroid and Antigeroid Syndromes

loci are involved, they may share common pathogenetic mechanisms, particularly RNA toxicity (Meola and Cardani 2015). DM1 is thought to be caused by triplet repeat expansions (CTG) in $D M P K$ (dystrophia myotonica-protein kinase), whereas DM2 is thought to be the result of repeat expansions in CNBP (CCHC-type zinc finger, nucleic acid binding protein) and, perhaps, other loci (Meola and Cardani 2015). When transcribed into CUG-containing RNA, mutant transcripts aggregate as nuclear foci that sequester RNA-binding proteins, resulting in a spliceopathy of downstream effector genes and accounting for the pleiotropic features. Avariety of pathogenetic mechanisms have been suggested (Meola and Cardani 2015), but there is some concern that these might be downstream events (Bachinski et al. 2014). Once the fundamental pathogenetic mechanisms have been fully clarified, it will be important to seek evidence of their roles in normative aging.

\section{Berardinelli-Seip Congenital Lipodystrophy}

Given the often profound metabolic disturbances associated with generalized lipodystrophies, such disorders have been of interest to geroscientists at least since a 1978 review that included the Seip syndrome in a compilation of human genetic disorders of potential relevance to the pathobiology of aging (Martin 1978). Insulin resistance, fatty liver, hypertriglyceridemia, type 2 diabetes mellitus, and other progeroid features noted below warrant its consideration as a segmental progeroid syndrome.

A valuable review of the pathophysiologies of a wide range of both genetic and acquired lipodystrophies has recently been published, including the several genetic variants of the Seip syndrome (Nolis 2014). All currently recognized forms of the latter are autosomal recessive in nature. The type 1 disorder is caused by mutations at AGPAT2, which codes for 1-acylglycerol-3-phosphate $O$-acyltransferase-2, an enzyme involved in de novo phospholipid biosynthesis. Type 2 is caused by mutations at BSCL2 (Berardinelli-Seip congenital lipodystrophy 2, also known as Seipin), which codes for a transmembrane protein that, like AGPAT2, is localized to the endoplasmic reticulum and participates in the control of lipid droplet formation and adipocyte differentiation. The type 3 disorder involves mutations at CAV1, or caveolin 1, a plasma membrane scaffolding protein and oncogene. Finally, the type 4 disorder is associated with mutations at PTRF, coding for the polymerase I and transcript-release factor, which is required for dissociation of a transcription complex and is also involved in the organization of the caveolae of plasma membranes. These mutations result in variable expressions of striking losses of normal adipose tissue and abnormal accumulations of lipids in various viscera, including skeletal muscle, liver, and heart. In addition to the regional atrophy of subcutaneous tissues that is so common in normative aging, one also observes type 2 diabetes mellitus (Lawson 2009), cardiovascular lesions (Nelson et al. 2013) often associated with lipid abnormalities, sometimes with multiple xanthomas (Machado et al. 2013), psychomotor abnormalities (Wei et al. 2013), and what some regard as secondary abnormalities of mitochondrial oxidative phosphorylation (Jeninga et al. 2012). Gastrointestinal polyps, a common benign feature of normative aging, have also been observed (Agrawala et al. 2014).

Like all segmental progeroid syndromes, there are of course discordances with what one observes in normative aging, the most dramatic of which is the striking muscular hypertrophy associated with Berardinelli-Seip congenital lipodystrophy.

\section{EXAMPLES OF UNIMODAL PROGEROID SYNDROMES}

\section{Dementias of the Alzheimer Type}

We use here the nomenclature of "dementias of the Alzheimer type" as a heuristic device to emphasize the need to consider the hypothesis that there may be several age-related independent pathogenetic pathways converging on a final common pathway that involves the processing of the $\beta$ amyloid precursor protein (APP) for the synthesis of what are currently considered to be the major neurotoxic moieties-oligomers 
F.M. Hisama et al.

and fibrils of amyloid $\beta$ peptides, particularly those derived from $A \beta 1-42$ (Ow and Dunstan 2014). Aggregates of the hyperphosphorylated microtubule-associated protein tau (Nisbet et al. 2015) are often considered to be downstream pathological events, as is microglia-mediated neuroinflammation (Tang and Le 2015). Given the striking exponential increases in agespecific incidence and prevalence of the common sporadic forms of DATs (Larson et al. 1992), it is surprising that there has been comparatively little attention given to the underlying intrinsic processes of aging that "set the stage" for the emergence of this disorder(s).

Although aging is the major risk factor for the emergence of DATs, by far the most striking genetic risk factor for the common sporadic late onset forms of the disease is the epsilon 4 allele of the gene that codes for the synthesis of apolipoprotein E (APOE4) (Corder et al. 1993). There are also rare familial, earlier onset forms of the disease caused by autosomal dominant mutations at three loci involved in the synthesis of amyloid $\beta$ : the $\beta$ amyloid precursor gene $(A P P)$, presenilin 1 (PS1), and presenilin 2 (PS2) (Chouraki and Seshadri 2014).

Although the most frequent $A P O E$ allele in European and North American populations is the E3 allele, the E4 allele is thought to be the ancestral allele, as it is found in nonhuman primates and in fossil DNA sequences of two Denisovans, members of an ancient species of hominids (McIntosh et al. 2012). An attractive hypothesis for why E4 may have evolved in nonhuman primates and early hominids and why the allele may persist today is that it may protect us from lipotropic pathogens (Martin 1999). There is, in fact, some evidence that the allele protects against malaria (Fujioka et al. 2013).

A range of potential mechanisms that underlie the vulnerability of E4 carriers to DATs has been recently reviewed (Kim et al. 2014). Although a differential effect of APOE alleles on the clearance of amyloid $\beta$ has been widely considered, there are several other possible mechanisms, certainly including those that may be related to an intrinsic deficiency in the delivery of lipids to maintain synaptic plasticity. Of special interest in this context is evidence that $\mathrm{E} 4$ carriers are deficient in repairing a variety of injuries, including those involved in the recovery from strokes and myocardial infarctions (Corder et al. 2000).

DATs have been considered by some investigators to be part of a group of neurodegenerative disorders resulting from deficiencies in DNA repair, with emphasis on the impacts on mitochondrial dysfunction for the case of DATs (Jeppesen et al. 2011). Impacts on cell cycle regulation and genomic integrity have also been related to APP functions (Chen et al. 2014). Thus, given further research, at least some forms of DATs may yet prove to be another example of a disorder of aging related to genomic instability.

\section{Parkinson's Disease}

Parkinson's disease (PD) affects $>$ one million people in the United States, and $>$ four million people worldwide. PD is a neurodegenerative disease characterized by bradykinesia, resting tremor, rigidity, postural instability, and responsiveness to dopaminergic therapy. Additional features include rapid eye movement (REM) behavior sleep disorder, depression, visual hallucinations, and dementia (Berg et al. 2014). Idiopathic PD occurs at older ages, is usually sporadic, and at autopsy, is characterized by neuronal loss (particularly of the pigmented neurons of the substantia nigra), astrocytic gliosis, and characteristic inclusions (Lewy bodies and dystrophic neurites). "Parkinsonism" is an umbrella term that includes monogenic and environmental (toxic) disorders with Parkinsonian features.

Great progress has been made in the identification of monogenic causes of PD, which can be clinically indistinguishable from idiopathic $\mathrm{PD}$, especially those resulting in juvenile Parkinsonism (onset before age $20 \mathrm{yr}$ ), and early-onset PD (onset before age $50 \mathrm{yr}$ ). However, only $\sim 15 \%$ of PD is early-onset (a higher proportion of which are genetically determined); $85 \%$ of PD cases are of the late-onset variety. Mutated genes that cause early-onset PD include 
those inherited as autosomal recessive traits (PARKIN, PINK1, DJ1) and those inherited as autosomal dominant traits (SCNA, which encodes $\alpha$-synuclein, a key component of the intraneuronal Lewy body inclusions, and $L R R K 2$ ) (Klein and Schlossmacher 2006). Identification of mutations in multiple genes sufficient to cause PD has highlighted the critical roles of sensing redox equilibrium and of mitochondrial dysfunction, including the importance of maintaining mitochondrial integrity in aging neurons. Although mutations in the genes causing early onset $\mathrm{PD}$ are rare in idiopathic forms of $\mathrm{PD}$, mutations in the $L R R K 2$ gene encoding a leucine rich kinase cause both late-onset familial PD as well as 1\%-3\% of sporadic late-onset cases of PD (Farrer et al. 2005).

Idiopathic, sporadic, late-onset PD (the most common type) is considered a complex trait. Its onset is modified by aging and environmental factors that include exposures to neurotoxins, caffeine intake, and cigarette smoking. The latter poses the paradox that it protects against PD despite the characterization of cigarette smoke as a "gerontogen" — an agent that accelerates multiple features of aging (Martin 1987; Bernhard et al. 2007). Both epigenetic and genetic factors are of course also considered to contribute to susceptibilities to this complex sporadic, late-onset disorder. Polymorphic variants in multiple loci have been implicated, including some bearing mutations involved in early onset familial forms. Examples include UCHL1 (PARK5), which encodes a ubiquitin carboxy-terminal hydrolase, and a locus coding for glucocerebrosidase $\beta$ (GBA) (Nichols et al. 2009; Miyake et al. 2012).

In summary, genetic studies of both familial and sporadic forms of PD (both early-onset and late onset forms of $\mathrm{PD}$ ) have yielded a new basis for understanding its pathogenesis and a wealth of targets for translational research and therapeutic interventions.

\section{Xeroderma Pigmentosa (XP)}

Given that virtually all human beings have variable degrees of exposure to ultraviolet light, it is not surprising that there is overlap in the age- related phenotypes seem in patients with this set of rare autosomal recessive UV hypersensitive disorders and the sun-exposed tissues of most of us as we age, including skin atrophy, actinic keratosis, hypo and hyperpigmentations, and a range of common geriatric neoplasms of the skin, including basal cell carcinomas, squamous carcinomas and melanomas. Concordances with how individuals usually age are also seen among some of the many eye pathologies in these patients, including ocular cataracts, drusen, keratitis, and pterygiums. Less intuitive overlaps involve neurological disorders such as hearing loss, cortical atrophy, ventricular dilatation, and impaired cognitive functions (Karass et al. 2014). Given this broader array of phenotypes, some might conclude that XP might be better classified under segmental progeroid syndromes. There are substantial variations in the extent to which such ancillary features are expressed, however, whereas the skin lesions are universally present and very severe. Moreover, although it seems reasonable to expect genomic instability to contribute to normative central nervous system (CNS) aging and its associated degenerative disorders, there is as yet no compelling evidence that this is a major contributor. Current research is more focused on alterations in proteostasis (Powers et al. 2009; Ben-Gedalya and Cohen 2012).

Initially described by a Hungarian physician in 1874, it was not until 1968 when James Cleaver made the seminal observation that the disease was caused by a defect in DNA repair (DiGiovanna and Kraemer 2012). We now know that there are eight different genetic loci at which bi-allelic mutations are involved in such defective DNA repair. Seven of them (XPA through XPG) are the result of aberrations in nucleotide excision repair, while the eighth form is the result of mutations in DNA polymerase $\eta$, which is involved in translesion DNA synthesis (Karass et al. 2014).

Transcription coupled repair is an area of interest in XP as well as in the Cockayne syndrome (see the discussion above). TF11H, a nine-subunit general transcription factor, plays a key role in that modality of DNA repair (O'Gorman et al. 2005). 
F.M. Hisama et al.

\section{Attenuated Familial Polyposis}

There is a range of gene mutations associated with highly penetrant precancerous and frankly malignant neoplasms of the gastrointestinal tract, notably of the colon (Jasperson 2012). These provide potentially informative clues for the role of biological aging in the genesis of a major type of human cancer, one whose agespecific incidence continues to rise exponentially well into the eighth decade of life. Mathematical modeling of such data has given support for the parallel process hypothesis, namely that multiple routes exist to the formation of cancer (Brody 2009). The complex genetic picture alluded to above is certainly consistent with that hypothesis. In keeping with the theme of this review, it is not surprising that there is strong evidence for genomic instability as a dominant factor in the pathogenesis of colon cancer (Rao and Yamada 2013). Relevant mutations include those involving mismatch repair of DNA (Durno et al. 2015) and germ line mutations in PolE and PolD (Valle et al. 2014).

We have here chosen one example of the multiple pathways to neoplasia-an autosomal dominant gene mutation that illustrates a type of gene action associated with a late onset form of colon cancer, one that would therefore more closely fit with what is seen in usual aging. Although this example, attenuated familial adenomatous polyposis, does not directly involve aberrations in DNA repair, it is of interest because its mutations are in unusual domains $\left(3^{\prime}\right.$ and $\left.5^{\prime}\right)$ of a gene $(A P C$, adenomatous polyposis coli) (Ibrahim et al. 2014). More common mutations elsewhere in this gene result in much more virulent, earlier onset forms of the disorder, which involves the loss of a tumor suppressor mechanism involving WNT signaling (www.genecards.org/cgi-bin/carddisp .pl?gene=APC).

\section{AGE-RELATED MACULAR DEGENERATION}

Age-related macular degeneration (AMD) is the commonest form of blindness among geriatric patients and is clearly coupled to processes of aging, although environmental factors, notably cigarette smoking, are important variables (Ratnapriya and Chew 2013). Allelic variations at some 20 different genetic loci have so far been described as being pathogenetically significant for the several classifications of the disorder, which may require "multiple hits" for its full expression (Fritsche et al. 2014). Since the seminal 2005 discovery of the importance of mutations at the complement factor $\mathrm{H}$ locus (Klein et al. 2005), a number of studies have highlighted the importance of oxidative stress, inflammation and the immune system in its pathogenesis (Gao et al. 2015), a view that fits with an emerging theme in geroscience referred to as “inflammaging” (Franceschi et al. 2007).

\section{Osteoporosis}

As both females and males age, especially females, there is a gradual loss of bone mineral density (BMD) such that affected individuals are prone to fractures of bone. Before the era of modern surgical techniques and effective antibiotic management, a sadly common clinical geriatric scenario was death from pneumonia of an aging female with some degree of sarcopenia and problems with balance who, as a result of loss of BMD, suffers a serious fracture of the hip followed by prolonged immobility. Useful clinical assays of BMD, including dual energy X-ray absorptiometry (DXA) (Nayak et al. 2015), have permitted large-scale epidemiological studies of osteoporosis. Using statistical criteria for the loss of BMD as compared with healthy young adults, estimates suggest that perhaps $8 \%$ of men and $30 \%$ of women over the age of 50 are osteoporotic (Kwan 2015).

Although most investigators emphasize a pathogenesis based on an imbalance between the rates of generation of new bone via the proliferation of osteoblasts and the rates of bone destruction via the proliferation and activities of osteoclasts, additional factors involving the endocrine and neuromuscular systems as well as nutrition are thought to be of importance (Kwan 2015). More than 60 genetic loci have been alleged to be associated with osteoporosis and some 15 have been associated with susceptibility to fractures, but large confirmational 
studies will be required, especially given that only $\sim 5 \%$ of the heritability is so far explained by current genetic studies (Clark and Duncan 2015). Given strong evidence of the involvement of at least three biochemical pathways, however, (Clark and Duncan 2015), it seems likely that advances in precision medicine will indeed be capable of identifying those individuals at substantial risk and, moreover, clinically useful translational interventions tailored to affected individuals, some of which will hopefully be guided by studies of individuals who are exceptionally resistant to the age-related loss of BMD.

\section{Atherosclerosis}

Atherosclerosis is a major form of arteriosclerosis ("hardening of the arteries") (Fishbein and Fishbein 2009). The literature on atherogenesis, its pathology, and its relationships to the biology of aging, to the metabolism of lipids, to inflammation, and to genetics is vast. Only a few major points can be made in the context of this review. The first point to emphasize is that cardiovascular diseases, predominately ischemic heart disease and strokes caused by atherosclerosis, remain the major causes of death in our society (www.cdc.gov/nchs/ fastats/leading-causes-of-death.htm). Second, the detection of high frequencies of calcified arterial lesions among the remains of humans who populated ancient civilizations is consistent with the hypothesis that it has always been an important disease of our species (Thomas et al. 2014). Third, aging is quite clearly a major risk factor in the emergence of the disease (Wang and Bennett 2012). DNA damage and repair, oxidative stress, telomere shortening, replicative senescence, apoptosis, inflammation, and mitochondrial dysfunctions are among the many processes of aging that have been associated with the disease (Wang and Bennett 2012; Sobenin et al. 2014; Wang et al. 2014).

Considering only coronary artery atherosclerosis, some 153 genome-wide associations have so far been identified, of which 56 have been validated, yet these $\sim 200$ loci, even if fully validated, can explain only $\sim 10 \%$ of the genetic variance for the disorder (Bjorkegren et al. 2015). Older classical studies had already identified very significant gene mutations, most notably those involving the low-density lipoprotein receptor (Goldstein et al. 1975). Moreover, elsewhere in this review, we have noted the important contributions of mutations at the WRN and LMNA loci.

To return to the earlier point regarding the ancient origins of the disease, an interesting hypothesis suggests that atherosclerosis may be a price we have paid for the role of scavenger receptors of macrophages in the defense against infectious agents (Martin 1998). That hypothesis was suggested by an experiment in which deletion of a macrophage scavenger receptor from a mouse model of atherosclerosis resulted in the anticipated amelioration of the atherosclerosis (because macrophages bearing oxidized lipoproteins are key components of atherogenesis), but marked vulnerability of these mice to infectious agents (Suzuki et al. 1997).

\section{EXAMPLES OF UNIMODAL ANTIGEROID ALLELES}

\section{Dementias of the Alzheimer Type}

The fact that the APOE4 allele is by far the major genetic risk factor for the sporadic, late-onset forms of DATs has been discussed above. The observation that the APOE2 allele is protective, however (Corder et al. 1994), has had comparatively much less attention, as evidenced by searches of PubMed for "APOE4 and Alzheimer's disease" versus "APOE2 and Alzheimer's disease." As of this writing, those numbers are, respectively, 3201 versus 432 . This, plus the fact that it is so difficult to find other wellestablished examples of unimodal antigeroid alleles, supports a major theme of this review, namely a plea for the need of much more research on this topic. For the present example, the importance of such research is not only relevant to the disease entities in question, DATs, it is also relevant to the broader issue of gene actions related to the heritability of longevity. The APOE2 allele is among those that contribute to 
F.M. Hisama et al.

this heritability, which has been estimated to be of the order of $25 \%-33 \%$ (Drenos and Kirkwood 2010).

A recent review of the role of the APOE2 allele in DATs, with the apt title beginning with "The forgotten APOE allele" considers various potential mechanisms of gene actions for this forgotten allele (Suri et al. 2013). These investigators consider a very wide range of potential mechanisms together with lines of supportive and conflicting lines of evidence. These include resistance of the apolipoprotein to denaturation, more favorable protein-protein interactions, a role in resisting the transformation of amyloid $\beta$ monomers to cytotoxic oligomers, enhanced degradation and clearance of depositions of amyloid $\beta$, enhanced protection of neurons from apoptotic death, enhancement of anti-inflammatory and antioxidant functions, a role in decreasing the levels of neurofibrillary tangles, and promotion of synaptic integrity. These investigators properly conclude that much more research is required, including research that differentiates the above properties from that of the more prevalent E3 allele. Support for gene actions related to enhanced morphologies of dendrites and antioxidant functions is emphasized.

\section{Atherosclerosis}

Given the above reference to evidence for a role of the APOE2 alleles in the enhancement of longevity, readers will perhaps be puzzled by the fact that homozygosity for that allele is associated with dysbetalipoproteinemia (type III hyperlipoproteinemia), a cause of "accelerated" atherogenesis (Phillips 2014). Thus, one could argue that the wild-type allele in most developed societies, $A P O E 3$, could be interpreted as being protective. Given the complex pathogenesis of this disorder, one can imagine a large number of allelic variants that are likely to provide even greater protection. An interesting effort to provide support for that scenario comes from recent in vivo gene expression studies of aortic cells from strains of pigeons that, under comparable conditions of husbandry and with comparable levels of serum cholesterol, are ei- ther highly susceptible (White Carneau) or highly resistant (Show Racer) to the spontaneous development of atherosclerosis (Anderson et al. 2013). Although there is evidence of a major autosomal recessive gene responsible for these contrasting phenotypes, the study revealed some 48 differentially expressed loci that fell into multiple biochemical genetic pathways, including striking divergences in cytoskeletal remodeling, proteasome activity, cellular respiration, and the immune response, thereby revealing families of loci for which human polymorphic variants may be of relevance to different pathways toward relative resistance to the disorder. An independent complementary study on atherosclerosis-resistant versus atherosclerosis-susceptible Japanese quails revealed seven loci supporting the pathogenetic importance of cholesterol metabolism ( $\mathrm{Li}$ et al. 2012). This has, of course, been well established for human atherogenesis, but deserves much more investigation regarding alleles providing resistance in human subjects.

There are many potentially fruitful areas of research regarding gene actions that may protect human subjects from atherosclerosis. One example might involve the differential regulation of the clonal senescence of cells of the vascular wall, as there is evidence of diminished clonal proliferation of vascular somatic cells from the abdominal aorta, which shows substantially more atherosclerosis than the thoracic aorta (Martin and Sprague 1972, 1973). Of interest in this context is the observation that significantly greater cloning efficiencies could be obtained from the aortic vascular wall cells from a long lived murine species (Peromyscus leukopus) as compared the laboratory mouse and that the clonal efficiencies from both systematically declined during aging (Martin et al. 1983). Variations in telomere function and structure could be one of the relevant underlying molecular variables (Chang and Harley 1995; Okuda et al. 2000).

The most recent actionable example of a unimodal antigeroid syndrome related to atherogenesis derives from observations of exceedingly low levels of LDL cholesterol associated with loss-of-function mutations at PCSK9, 
including haploinsufficiency (Awan et al. 2014; Roberts 2015). Gain-of-function mutations at PCSK9 ( proprotein convertase subtilisin/kexin type 9) were discovered as the third cause of familial hypercholesterolemia (Awan et al. 2014). Drug companies have now introduced monoclonal antibodies against that gene product in an effort to emulate the effects of loss-offunction mutations that appear to protect subjects from atherosclerosis and ischemic heart disease (www.nytimes.com/aponline/2015/06/ 09/us/ap-us-cholesterol-drug-fda.html).

\section{Genetic Resistance to Environmental Carcinogens}

There is no doubt that one of the secrets to the avoidance of cancer (especially lung cancer) and to increasing one's chances of living to the tenth and eleventh decades of life is to avoid cigarette smoke (Wilhelmsen et al. 2015). But why do some heavy cigarette smokers live well into their tenth and eleventh decades free of lung cancer (Rajpathak et al. 2011)? There is a very large literature on candidate polymorphic variants that can provide protection against some of the large numbers of carcinogenic compounds in cigarette smoke, a review of which is beyond the scope of this review. Polygenic models (Dragani et al. 1996; Galvan et al. 2008) are likely to be the most satisfactory approaches to uncovering various patterns of resistance and susceptibility as we approach the era of whole gene sequencing and precision medicine (Esplin et al. 2014)

\section{CONCLUSIONS AND FUTURE DIRECTIONS}

We have seen how skilled phenotypic characterizations, when combined with careful family histories and the modern tools of genomic analysis, has led to the definition of a subset of heritable disorders that show many, but not all, features consistent with accelerated rates of aging together with increased vulnerabilities to a range of geriatric disorders. These have become known as "segmental progeroid syndromes" (Martin 1978). Remarkably, biochemical genetic studies of these mutations have provided strong support for a fundamental mechanism of aging-genomic instability (Fig. 1C). This mechanism of aging appears to have deep evolutionary roots, as exemplified by research on the limited replicative life spans of budding yeast mother cells (Xie et al. 2015).

We have also given a few examples of genetic disorders that predominately impact on a single major geriatric disorder- "unimodal progeroid disorders" (Martin 1982). As such, they can elucidate biochemical genetic mechanisms, thus opening the door to translational efforts in prevention and treatment. An exemplary example has been the discovery that all three autosomal dominant mutations responsible for early onset familial forms of dementias of the $\mathrm{Alz}$ heimer type point to the pivotal role of the differential processing of the $\beta$ APP (Nhan et al. 2015).

With an eye toward the future, we suggest new efforts by geneticists and others to begin to define allelic variants that provide unusually robust resistance to fundamental mechanisms of aging or to specific physiological domains that typically decline during aging. Although productive research along these lines is being performed by colleagues who focus on the genetic basis of unusually long life spans (see Milman and Barzilai 2015), we argue for two additional avenues of research. The first could involve a somatic cell genetic approach that uses various types of immortalized human somatic cells. Examples could include searches for mutations or copy number variations that result in unusual resistance to agents that produce genomic instability, such as DNA cross-linking agents (Ogburn et al. 1997), epigenetic drifts in gene expression (Martin 2009), mitochondrial dysfunction (Meyer et al. 2013), or altered proteostasis (Morimoto and Cuervo 2014), each of which have been proposed as mechanisms of aging. Of greater and timelier clinical significance, however, would be research that uncovers unusual alleles that could explain the mechanisms of exceptionally robust resistance to declines in such phenotypes as cognition, sarcopenia, cardiovascular function, etc. This might be achieved via longitudinal studies performed during middle ages, when the force of natural selection has waned and when processes of 
F.M. Hisama et al.

aging begin to translate into varying degrees of pathophysiology, typically in the absence of significant comorbidity (Martin 2002). Another approach could involve an initiative comparable to Seattle's Sage Bionetworks, which searches for individuals who have genetic changes expected to cause severe illness but who remain perfectly healthy (en.wikipedia.org/wiki/Sage_ Bionetworks). Why is this important for the longevity dividend initiative, which argues for a fundamental slowing of the intrinsic rate of aging as a pathway toward the postponement of "all" forms of age-related pathophysiology? The answer, we believe, is given by two of the classical evolutionary biological theories of aging-antagonistic pleiotropy (Williams 1957) and mutation accumulation (Medawar 1952). Both of these mechanisms predict what might be called "private susceptibilities" to very particular domains of aging. These theories predict idiosyncratic expressions of senescent phenotypes because of the uniqueness of individual genomes, expososomes, somatic mutations, and epigenetic drifts of gene expression. Thus, although major interventions in basic mechanisms of aging may well provide the robustness and resilience required for extended life spans, they may not guarantee freedom from individual "Achilles heels" that result in departures from robust health spans.

\section{ACKNOWLEDGMENTS}

We thank Professor M. Stephen Meyn, a medical geneticist at the University of Toronto, for his helpful review of this manuscript. We thank the National Cancer Institute and the National Institute on Aging for their long term support of the University of Washington's International Registry of Werner Syndrome (5R24AG04232803,-S1).The Photo of Werner syndrome patient, registry\#ROMA1010, was provided by Dr. Giovanni Neri, Universit Cattolica, Roma, Italy.

\section{REFERENCES}

${ }^{*}$ Reference is also in this collection.

Agrawala RK, Choudhury AK, Mohanty BK, Baliarsinha AK. 2014. Berardinelli-Seip congenital lipodystrophy:
An autosomal recessive disorder with rare association of duodenocolonic polyps. J Pediatr Endocrinol Metab 27: 989-991.

Anderson JL, Ashwell CM, Smith SC, Shine R, Smith EC, Taylor RL Jr. 2013. Atherosclerosis-susceptible and atherosclerosis-resistant pigeon aortic cells express different genes in vivo. Poult Sci 92: 2668-2680.

Andres V, Gonzalez JM. 2009. Role of A-type lamins in signaling, transcription, and chromatin organization. J Cell Biol 187: 945-957.

Auerbach AD. 2009. Fanconi anemia and its diagnosis. $M u-$ tat Res 668: 4-10.

Awan Z, Baass A, Genest J. 2014. Proprotein convertase subtilisin/kexin type 9 (PCSK9): Lessons learned from patients with hypercholesterolemia. Clin Chem 60: 13801389.

Axford MM, Pearson CE. 2013. Illuminating CNS and cognitive issues in myotonic dystrophy: Workshop report. Neuromuscul Disord 23: 370-374.

Bachinski LL, Baggerly KA, Neubauer VL, Nixon TJ, Raheem O, Sirito M, Unruh AK, Zhang J, Nagarajan L, Timchenko LT, et al. 2014. Most expression and splicing changes in myotonic dystrophy type 1 and type 2 skeletal muscle are shared with other muscular dystrophies. Neuromuscul Disord 24: 227-240.

Baidas S, Chen TJ, Kolev V, Wong LJ, Imholte J, Qin N, Meck J. 2004. Constitutional trisomy 8 mosaicism due to meiosis II non-disjunction in a phenotypically normal woman with hematologic abnormalities. Am J Med Genet A 124A: 383-387.

Ben-Gedalya T, Cohen E. 2012. Quality control compartments coming of age. Traffic 13: 635-642.

Berg D, Postuma RB, Bloem B, Chan P, Dubois B, Gasser T, Goetz CG, Halliday GM, Hardy J, Lang AE, et al. 2014. Time to redefine PD? Introductory statement of the MDS Task Force on the definition of Parkinson's disease. Mov Disord 29: 454-462.

Bernhard D, Moser C, Backovic A, Wick G. 2007. Cigarette smoke-An aging accelerator? Exp Gerontol 42: 160-165.

Bjorkegren JL, Kovacic JC, Dudley JT, Schadt EE. 2015. Genome-wide significant loci: How important are they? Systems genetics to understand heritability of coronary artery disease and other common complex disorders. $J$ Am Col Cardiol 65: 830-845.

Blank A, Bobola MS, Gold B, Varadarajan S, Kolstoe DD, Meade EH, Rabinovitch PS, Loeb LA, Silber JR. 2004. The Werner syndrome protein confers resistance to the DNA lesions N3-methyladenine and $\mathrm{O}^{6}$-methylguanine: Implications for WRN function. DNA Repair (Amst) 3: 629-638.

Bloom D. 1954. Congenital telangiectatic erythema resembling lupus erythematosus in dwarfs; probably a syndrome entity. AMA Am J Dis Child 88: 754-758.

Brody JP. 2009. Parallel routes of human carcinoma development: Implications of the age-specific incidence data. PLoS ONE 4: e7053.

Capell BC, Collins FS. 2006. Human laminopathies: Nuclei gone genetically awry. Nat Rev Genet 7: 940-952.

Centore RC, Yazinski SA, Tse A, Zou L. 2012. Spartan/ C1orf124, a reader of PCNA ubiquitylation and a regu- 
lator of UV-induced DNA damage response. Mol Cell 46: 625-635.

Chaganti RS, Schonberg S, German J. 1974. A manyfold increase in sister chromatid exchanges in Bloom's syndrome lymphocytes. Proc Natl Acad Sci 71: 4508-4512.

Chang E, Harley CB. 1995. Telomere length and replicative aging in human vascular tissues. Proc Natl Acad Sci 92: 11190-11194.

Chatre L, Biard DS, Sarasin A, Ricchetti M. 2015. Reversal of mitochondrial defects with CSB-dependent serine protease inhibitors in patient cells of the progeroid Cockayne syndrome. Proc Natl Acad Sci 112: E2910-2919.

Chen L, Lee L, Kudlow BA, Dos Santos HG, Sletvold O, Shafeghati Y, Botha EG, Garg A, Hanson NB, Martin GM, et al. 2003. LMNA mutations in atypical Werner's syndrome. Lancet 362: 440-445.

Chen Y, Neve R, Zheng H, Griffin W, Barger S, Mrak R. 2014. Cycle on Wheels: Is APP key to the AppBp1 pathway? Austin Alzheimers Parkinsons Dis 1: id1008.

Cheung HH, Liu X, Canterel-Thouennon L, Li L, Edmonson C, Rennert OM. 2014. Telomerase protects Werner syndrome lineage-specific stem cells from premature aging. Stem Cell Rep 2: 534-546.

Chouraki V, Seshadri S. 2014. Genetics of Alzheimer's disease. Adv Genet 87: 245-294.

Clark GR, Duncan EL. 2015. The genetics of osteoporosis. Br Med Bull 113: 73-81.

Clifford R, Louis T, Robbe P, Ackroyd S, Burns A, Timbs AT, Colopy GW, Dreau H, Sigaux F, Judde JG, et al. 2013. $S A M H D 1$ is mutated recurrently in chronic lymphocytic leukemia and is involved in response to DNA damage. Blood 123: 1021-1031.

Corder EH, Saunders AM, Strittmatter WJ, Schmechel DE, Gaskell PC, Small GW, Roses AD, Haines JL, PericakVance MA. 1993. Gene dose of apolipoprotein E type 4 allele and the risk of Alzheimer's disease in late onset families. Science 261: 921-923.

Corder EH, Saunders AM, Risch NJ, Strittmatter WJ, Schmechel DE, Gaskell PC Jr, Rimmler JB, Locke PA, Conneally PM, Schmader KE, et al. 1994. Protective effect of apolipoprotein E type 2 allele for late onset Alzheimer disease. Nat Genet 7: 180-184.

Corder EH, Basun H, Fratiglioni L, Guo Z, Lannfelt L, Viitanen M, Corder LS, Manton KG, Winblad B. 2000. Inherited frailty. ApoE alleles determine survival after a diagnosis of heart disease or stroke at ages $85+$. Ann NYAcad Sci 908: 295-298.

Croteau DL, Popuri V, Opresko PL, Bohr VA. 2014. Human RecQ helicases in DNA repair, recombination, and replication. Annu Rev Biochem 83: 519-552.

Dale RC, Gornall H, Singh-Grewal D, Alcausin M, Rice GI, Crow YJ. 2010. Familial Aicardi-Goutieres syndrome due to SAMHD1 mutations is associated with chronic arthropathy and contractures. Am J Med Genet A 152A: 938-942.

De S, Kumari J, Mudgal R, Modi P, Gupta S, Futami K, Goto H, Lindor NM, Furuichi Y, Mohanty D, et al. 2012. RECQL4 is essential for the transport of p53 to mitochondria in normal human cells in the absence of exogenous stress. J Cell Sci 125: 2509-2522.
DiGiovanna JJ, Kraemer KH. 2012. Shining a light on xeroderma pigmentosum. J invest dermatol 132: 785-796.

Dragani TA, Canzian F, Pierotti MA. 1996. A polygenic model of inherited predisposition to cancer. FASEB $J$ 10: $865-870$.

Drenos F, Kirkwood TB. 2010. Selection on alleles affecting human longevity and late-life disease: The example of apolipoprotein E. PLoS ONE 5: e10022.

Drouin CA, Mongrain E, Sasseville D, Bouchard HL, Drouin M. 1993. Rothmund-Thomson syndrome with osteosarcoma. J Am Acad Dermatol 28: 301-305.

Durno CA, Sherman PM, Aronson M, Malkin D, Hawkins C, Bakry D, Bouffet E, Gallinger S, Pollett A, Campbell B, et al. 2015. Phenotypic and genotypic characterisation of biallelic mismatch repair deficiency (BMMR-D) syndrome. Eur J Cancer 51: 977-983.

Eriksson M, Brown WT, Gordon LB, Glynn MW, Singer J, Scott L, Erdos MR, Robbins CM, Moses TY, Berglund P, et al. 2003. Recurrent de novo point mutations in lamin A cause Hutchinson-Gilford progeria syndrome. Nature 423: 293-298.

Esplin ED, Oei L, Snyder MP. 2014. Personalized sequencing and the future of medicine: Discovery, diagnosis and defeat of disease. Pharmacogenomics 15: 1771-1790.

Fan L, DuPrez KT. 2015. XPB: An unconventional SF2 DNA helicase. Prog Biophys Mol Biol 117: 174-181.

Farrer M, Stone J, Mata IF, Lincoln S, Kachergus J, Hulihan M, Strain KJ, Maraganore DM. 2005. LRRK2 mutations in Parkinson disease. Neurology 65: 738-740.

Finch C, Kirkwood TBL. 2000. Chance, development, and aging. Oxford University Press, New York.

Fineman RM, Ablow RC, Howard RO, Albright J, Breg WR. 1975. Trisomy 8 mosaicism syndrome. Pediatrics 56: $762-767$.

Fishbein GA, Fishbein MC. 2009. Arteriosclerosis: Rethinking the current classification. Arch Pathol Lab Med 133: 1309-1316.

Franceschi C, Capri M, Monti D, Giunta S, Olivieri F, Sevini F, Panourgia MP, Invidia L, Celani L, Scurti M, et al. 2007. Inflammaging and anti-inflammaging: A systemic perspective on aging and longevity emerged from studies in humans. Mech Ageing Dev 128: 92-105.

Friedrich K, Lee L, Leistritz DF, Nurnberg G, Saha B, Hisama FM, Eyman DK, Lessel D, Nurnberg P, Li C, et al. 2010. WRN mutations in Werner syndrome patients: Genomic rearrangements, unusual intronic mutations and ethnicspecific alterations. Hum Genet 128: 103-111.

Fritsche LG, Fariss RN, Stambolian D, Abecasis GR, Curcio CA, Swaroop A. 2014. Age-related macular degeneration: Genetics and biology coming together. Annu Rev Genomics Hum Genet 15: 151-171.

Fujioka H, Phelix CF, Friedland RP, Zhu X, Perry EA, Castellani RJ, Perry G. 2013. Apolipoprotein E4 prevents growth of malaria at the intraerythrocyte stage: Implications for differences in racial susceptibility to Alzheimer's disease. J Health Care Poor Underserved 24: 70-78.

Galvan A, Falvella FS, Spinola M, Frullanti E, Leoni VP, Noci S, Alonso MR, Zolin A, Spada E, Milani S, et al. 2008. A polygenic model with common variants may predict lung adenocarcinoma risk in humans. Int J Can 123: 23272330. 
F.M. Hisama et al.

Gao J, Liu RT, Cao S, Cui JZ, Wang A, To E, Matsubara JA. 2015. NLRP3 inflammasome: Activation and regulation in age-related macular degeneration. Mediators Inflamm 2015: 690243.

German J, Bloom D, Passarge E. 1984. Bloom's syndrome XI. Progress report for 1983. Clin Genet 25: 166-174.

Goldstein JL, Dana SE, Brunschede GY, Brown MS. 1975. Genetic heterogeneity in familial hypercholesterolemia: Evidence for two different mutations affecting functions of low-density lipoprotein receptor. Proc Natl Acad Sci 72: $1092-1096$.

Gordon LB, Brown WT, Collins FS. 1993. Hutchinson-Gilford progeria syndrome. GeneReviews, University of Washington, Seattle.

Gordon LB, Massaro J, D'Agostino RB Sr, Campbell SE, Brazier J, Brown WT, Kleinman ME, Kieran MW, Progeria Clinical Trials C. 2014. Impact of farnesylation inhibitors on survival in Hutchinson-Gilford progeria syndrome. Circulation 130: 27-34.

Goto M, Miller RW, Ishikawa Y, Sugano H. 1996. Excess of rare cancers in Werner syndrome (adult progeria). Cancer Epidemiol Biomarkers Prev 5: 239-246.

Grein Cavalcanti L, Fatima Lyko K, Lins Fuentes Araujo R, Miguel Amenabar J, Bonfim C, Carvalho Torres-Pereira C. 2015. Oral leukoplakia in patients with Fanconi anaemia without hematopoietic stem cell transplantation. $\mathrm{Pe}$ diatr Blood Cancer 62: 1024-1026.

Gupta S, De S, Srivastava V, Hussain M, Kumari J, Muniyappa K, Sengupta S. 2014. RECQL4 and 553 potentiate the activity of polymerase $\gamma$ and maintain the integrity of the human mitochondrial genome. Carcinogenesis 35: 34-45.

Harper PS, Brook JD, Newman E. 2001. Myotonic dystrophy. WB Saunders, New York.

Hisama FM, Lessel D, Leistritz D, Friedrich K, McBride KL, Pastore MT, Gottesman GS, Saha B, Martin GM, Kubisch C, et al. 2011. Coronary artery disease in a Werner syndrome-like form of progeria characterized by low levels of progerin, a splice variant of lamin A. Am J Med Genet A 155A: $3002-3006$

Hoki Y, Araki R, Fujimori A, Ohhata T, Koseki H, Fukumura R, Nakamura M, Takahashi H, Noda Y, Kito S, et al. 2003. Growth retardation and skin abnormalities of the Recql4deficient mouse. Hum Mol Genet 12: 2293-2299.

Ibrahim A, Barnes DR, Dunlop J, Barrowdale D, Antoniou AC, Berg JN. 2014. Attenuated familial adenomatous polyposis manifests as autosomal dominant late-onset colorectal cancer. Eur J Hum Genet 22: 1330-1333.

Jaarsma D, van der Pluijm I, van der Horst GT, Hoeijmakers JH. 2013. Cockayne syndrome pathogenesis: Lessons from mouse models. Mech Ageing Dev 134: 180-195.

Jasperson KW. 2012. Genetic testing by cancer site: Colon (polyposis syndromes). Cancer J 18: 328-333.

Jeninga EH, de Vroede M, Hamers N, Breur JM, VerhoevenDuif NM, Berger R, Kalkhoven E. 2012. A patient with congenital generalized lipodystrophy due to a novel mutation in BSCL2: Indications for secondary mitochondrial dysfunction. JIMD Reps 4: 47-54.

Jeppesen DK, Bohr VA, Stevnsner T. 2011. DNA repair deficiency in neurodegeneration. Prog Neurobiol 94: 166200.
Kamath-Loeb AS, Shen JC, Schmitt MW, Loeb LA. 2012. The Werner syndrome exonuclease facilitates DNA degradation and high fidelity DNA polymerization by human DNA polymerase $\delta$. J Biol Chem 287: 12480-12490.

Kaneko H, Kondo N. 2004. Clinical features of Bloom syndrome and function of the causative gene, BLM helicase. Expert Rev Mol Diagn 4: 393-401.

Karass M, Naguib MM, Elawabdeh N, Cundiff CA, Thomason J, Steelman CK, Cone R, Schwenkter A, Jordan C, Shehata BM. 2014. Xeroderma pigmentosa: Three new cases with an in depth review of the genetic and clinical characteristics of the disease. Fetal Pediatr Pathol 34: $120-127$.

Kim J, Yoon H, Basak J, Kim J. 2014. Apolipoprotein E in synaptic plasticity and Alzheimer's disease: Potential cellular and molecular mechanisms. Mol Cells 37: 767-776.

Kitao S, Shimamoto A, Goto M, Miller RW, Smithson WA, Lindor NM, Furuichi Y. 1999. Mutations in RECQL4 cause a subset of cases of Rothmund-Thomson syndrome. Nat Genet 22: 82-84.

Klein C, Schlossmacher MG. 2006. The genetics of Parkinson disease: Implications for neurological care. Nat Clin Pract Neurol 2: 136-146.

Klein RJ, Zeiss C, Chew EY, Tsai JY, Sackler RS, Haynes C, Henning AK, SanGiovanni JP, Mane SM, Mayne ST, et al. 2005. Complement factor $\mathrm{H}$ polymorphism in age-related macular degeneration. Science 308: 385-389.

Kwan P. 2015. Osteoporosis: From osteoscience to neuroscience and beyond. Mech Ageing Dev 145C: 26-38.

Laberge L, Gagnon C, Dauvilliers Y. 2013. Daytime sleepiness and myotonic dystrophy. Curr Neurol Neurosci Rep 13: 340 .

Larson EB, Kukull WA, Katzman RL. 1992. Cognitive impairment: Dementia and Alzheimer's disease. Annu Rev Public Health 13: 431-449.

Laugel V. 2013. Cockayne syndrome: The expanding clinical and mutational spectrum. Mech Ageing Dev 134: 161170.

Lawson MA. 2009. Lipoatrophic diabetes: A case report with a brief review of the literature. J Adolesc Health 44: 94-95.

Lessel D, Saha B, Hisama F, Kaymakamzade B, Nurlu G, Gursoy-Ozdemir Y, Thiele H, Nurnberg P, Martin GM, Kubisch C, et al. 2014a. Atypical Aicardi-Goutieres syndrome: is the WRN locus a modifier? Am J Med Genet A 164A: $2510-2513$.

Lessel D, Vaz B, Halder S, Lockhart PJ, Marinovic-Terzic I, Lopez-Mosqueda J, Philipp M, Sim JC, Smith KR, Oehler J, et al. 2014b. Mutations in SPRTN cause early onset hepatocellular carcinoma, genomic instability and progeroid features. Nat Genet 46: 1239-1244.

Li X, Schulte P, Godin DV, Cheng KM. 2012. Differential mRNA expression of seven genes involved in cholesterol metabolism and transport in the liver of atherosclerosissusceptible and -resistant Japanese quail strains. Genet Sel Evol 44: 20.

Liebetrau W, Runge TM, Baumer A, Henning C, Gross O, Schindler D, Poot M, Hoehn H. 1997. Exploring the role of oxygen in Fanconi's anemia. Recent Results Cancer Res 143: 353-367.

Liu B, Wang J, Chan KM, Tjia WM, Deng W, Guan X, Huang JD, Li KM, Chau PY, Chen DJ, et al. 2005. Genomic 
instability in laminopathy-based premature aging. Nat Med 11: 780-785.

Liu Y, Rusinol A, Sinensky M, Wang Y, Zou Y. 2006. DNA damage responses in progeroid syndromes arise from defective maturation of prelamin A. J Cell Sci 119: 4644-4649.

Lord J, Lu AJ, Cruchaga C. 2014. Identification of rare variants in Alzheimer's disease. Front Genet 5: 369.

Machado PV, Daxbacher EL, Obadia DL, Cunha EF, Alves Mde F, Mann D. 2013. Do you know this syndrome? Berardinelli-Seip syndrome. An Bras Dermatol 88: 1011-1013.

Machwe A, Karale R, Xu X, Liu Y, Orren DK. 2011. The Werner and Bloom syndrome proteins help resolve replication blockage by converting (regressed) Holliday junctions to functional replication forks. Biochemistry 50: $6774-6788$.

Malatesta M, Cardani R, Pellicciari C, Meola G. 2014. RNA transcription and maturation in skeletal muscle cells are similarly impaired in myotonic dystrophy and sarcopenia: The ultrastructural evidence. Front Aging Neurosci 6: 196.

Marteijn JA, Lans H, Vermeulen W, Hoeijmakers JH. 2014. Understanding nucleotide excision repair and its roles in cancer and ageing. Nat Rev Mol Cell Biol 15: 465-481.

Martin GM. 1978. Genetic syndromes in man with potential relevance to the pathobiology of aging. Birth Defects Orig Art Ser 14: 5-39.

Martin GM. 1982. Syndromes of accelerated aging. Natl Cancer Inst Monogr 60: 241-247.

Martin GM. 1987. Interactions of aging and environmental agents: The gerontological perspective. Prog Clin Biol Res 228: $25-80$.

Martin GM. 1998. Atherosclerosis is the leading cause of death in the developed societies. Am J Pathol 153: 1319-1320.

Martin GM. 1999. APOE alleles and lipophylic pathogens. Neurobiol Aging 20: 441-443.

Martin GM. 2002. Help wanted: Physiologists for research on aging. Sci Aging Knowledge Environ 2002: vp2.

Martin GM. 2005. Genetic modulation of senescent phenotypes in Homo sapiens. Cell 120: 523-532.

Martin GM. 2009. Epigenetic gambling and epigenetic drift as an antagonistic pleiotropic mechanism of aging. Aging Cell 8: 761-764.

Martin GM. 2012. Stochastic modulations of the pace and patterns of ageing: Impacts on quasi-stochastic distributions of multiple geriatric pathologies. Mech Ageing Dev 133: $107-111$.

Martin GM, Oshima J. 2000. Lessons from human progeroid syndromes. Nature 408: 263-266.

Martin GM, Sprague CA. 1972. Clonal senescence and atherosclerosis. Lancet 2: 1370-1371.

Martin GM, Sprague CA. 1973. Symposium on in vitro studies related to atherogenesis. Life histories of hyperplastoid cell lines from aorta and skin. Exp Mol Pathol 18: 125-141.

Martin GM, Ogburn CE, Wight TN. 1983. Comparative rates of decline in the primary cloning efficiencies of smooth muscle cells from the aging thoracic aorta of two murine species of contrasting maximum life span potentials. Am J Pathol 110: 236-245.

McClintock D, Ratner D, Lokuge M, Owens DM, Gordon LB, Collins FS, Djabali K. 2007. The mutant form of lamin A that causes Hutchinson-Gilford progeria is a biomarker of cellular aging in human skin. PLoS ONE 2: e1269.

McIntosh AM, Bennett C, Dickson D, Anestis SF, Watts DP, Webster TH, Fontenot MB, Bradley BJ. 2012. The apolipoprotein $\mathrm{E}(A P O E)$ gene appears functionally monomorphic in chimpanzees (Pan troglodytes). PLoS ONE 7: e47760.

Medawar P. 1952. An unsolved problem in biology. H.K. Lewis, London.

Meola G, Cardani R. 2015. Myotonic dystrophies: An update on clinical aspects, genetic, pathology, and molecular pathomechanisms. Biochim Biophys Acta 1852: 594-606.

Merideth MA, Gordon LB, Clauss S, Sachdev V, Smith AC, Perry MB, Brewer CC, Zalewski C, Kim HJ, Solomon B, et al. 2008. Phenotype and course of Hutchinson-Gilford progeria syndrome. N Engl J Med 358: 592-604.

Meyer JN, Leung MC, Rooney JP, Sendoel A, Hengartner MO, Kisby GE, Bess AS. 2013. Mitochondria as a target of environmental toxicants. Toxicol Sci 134: 1-17.

Meyn MS. 1993. High spontaneous intrachromosomal recombination rates in ataxia-telangiectasia. Science 260: 1327-1330.

* Milman S, Barzilai N. 2015. Dissecting the mechanisms underlying unusually successful human healthspan and lifespan. Cold Spring Harb Persect Med doi: 10.1101/ cshperspect.a025098.

Miyake Y, Tanaka K, Fukushima W, Kiyohara C, Sasaki S, Tsuboi Y, Yamada T, Oeda T, Shimada H, Kawamura N, et al. 2012. UCHL1 S18Y variant is a risk factor for Parkinson's disease in Japan. BMC Neurol 12: 62.

Morimoto RI, Cuervo AM. 2014. Proteostasis and the aging proteome in health and disease. J Gerontol A Biol Sci Med Sci 69 (Suppl. 1): S33-S38.

Nayak S, Edwards DL, Saleh AA, Greenspan SL. 2015. Systematic review and meta-analysis of the performance of clinical risk assessment instruments for screening for osteoporosis or low bone density. Osteoporos Int 26: $1543-$ 1554.

Nelson MD, Victor RG, Szczepaniak EW, Simha V, Garg A, Szczepaniak LS. 2013. Cardiac steatosis and left ventricular hypertrophy in patients with generalized lipodystrophy as determined by magnetic resonance spectroscopy and imaging. Am J Cardiol 112: 1019-1024.

Neveling K, Endt D, Hoehn H, Schindler D. 2009. Genotype-phenotype correlations in Fanconi anemia. Mutat Res-Fund Mol M 668: 73-91.

Nhan HS, Chiang K, Koo EH. 2015. The multifaceted nature of amyloid precursor protein and its proteolytic fragments: friends and foes. Acta Neuropathol 129: 1-19.

Nichols WC, Pankratz N, Marek DK, Pauciulo MW, Elsaesser VE, Halter CA, Rudolph A, Wojcieszek J, Pfeiffer RF, Foroud T, et al. 2009. Mutations in GBA are associated with familial Parkinson disease susceptibility and age at onset. Neurology 72: 310-316. 
F.M. Hisama et al.

Nisbet RM, Polanco JC, Ittner LM, Gotz J. 2015. Tau aggregation and its interplay with amyloid- $\beta$. Acta Neuropathol 129: 207-220.

Nolis T. 2014. Exploring the pathophysiology behind the more common genetic and acquired lipodystrophies. $J$ Hum Genet 59: 16-23.

Ogburn CE, Oshima J, Poot M, Chen R, Hunt KE, Gollahon KA, Rabinovitch PS, Martin GM. 1997. An apoptosisinducing genotoxin differentiates heterozygotic carriers for Werner helicase mutations from wild-type and homozygous mutants. Hum Genet 101: 121-125.

O'Gorman W, Thomas B, Kwek KY, Furger A, Akoulitchev A. 2005. Analysis of U1 small nuclear RNA interaction with cyclin H. J Biol Chem 280: 36920-36925.

Okuda K, Khan MY, Skurnick J, Kimura M, Aviv H, Aviv A. 2000. Telomere attrition of the human abdominal aorta: relationships with age and atherosclerosis. Atherosclerosis 152: 391-398.

Olive M, Harten I, Mitchell R, Beers JK, Djabali K, Cao K, Erdos MR, Blair C, Funke B, Smoot L, et al. 2010. Cardiovascular pathology in Hutchinson-Gilford progeria: Correlation with the vascular pathology of aging. Arterioscler Thromb Vasc Biol 30: 2301-2309.

Oostra AB, Nieuwint AW, Joenje H, de Winter JP. 2012. Diagnosis of Fanconi anemia: Chromosomal breakage analysis. Anemia 2012: 238731.

Oshima J, Hisama FM. 2014. Search and insights into novel genetic alterations leading to classical and atypical Werner syndrome. Gerontology 60: 239-246.

Oshima J, Martin GM, Hisama FM. 2014. Werner syndrome. In GeneReviews(R) (ed. Pagon RA, Adam MP, Bird TD, Dolan CR, Fong CT, Smith RJH, Stephens K). University of Washington, Seattle, WA

Ow SY, Dunstan DE. 2014. A brief overview of amyloids and Alzheimer's disease. Protein Sci 23: 1315-1331.

Pagano G, Shyamsunder P, Verma RS, Lyakhovich A. 2014. Damaged mitochondria in Fanconi anemia-An isolated event or a general phenomenon? Oncoscience 1: 287-295.

Palles C, Cazier JB, Howarth KM, Domingo E, Jones AM, Broderick P, Kemp Z, Spain SL, Guarino E, Salguero I, et al. 2013. Germline mutations affecting the proofreading domains of POLE and POLD1 predispose to colorectal adenomas and carcinomas. Nat Genet 45: $136-$ 144.

Pelosini C, Martinelli S, Ceccarini G, Magno S, Barone I, Basolo A, Fierabracci P, Vitti P, Maffei M, Santini F. 2014. Identification of a novel mutation in the polymerase delta 1 (POLD1) gene in a lipodystrophic patient affected by mandibular hypoplasia, deafness, progeroid features (MDPL) syndrome. Metabolism 63: 1385-1389.

Phillips MC. 2014. Apolipoprotein E isoforms and lipoprotein metabolism. IUBMB Life 66: 616-623.

Powers ET, Morimoto RI, Dillin A, Kelly JW, Balch WE. 2009. Biological and chemical approaches to diseases of proteostasis deficiency. Annu Rev Biochem 78: 959-991.

Quentin S, Cuccuini W, Ceccaldi R, Nibourel O, Pondarre C, Pages MP, Vasquez N, d'Enghien CD, Larghero J, de Latour RP, et al. 2011. Myelodysplasia and leukemia of Fanconi anemia are associated with a specific pattern of ge- nomic abnormalities that includes cryptic RUNX1/ AML1 lesions. Blood 117: E161-E170.

Rajpathak SN, Liu Y, Ben-David O, Reddy S, Atzmon G, Crandall J, Barzilai N. 2011. Lifestyle factors of people with exceptional longevity. J Am Geriatr Soc 59: 1509_ 1512.

Rao CV, Yamada HY. 2013. Genomic instability and colon carcinogenesis: From the perspective of genes. Front Oncol 3: 130.

Ratnapriya R, Chew EY. 2013. Age-related macular degeneration-Clinical review and genetics update. Clin Genet 84: $160-166$.

Rice GI, Bond J, Asipu A, Brunette RL, Manfield IW, Carr IM, Fuller JC, Jackson RM, Lamb T, Briggs TA, et al. 2009. Mutations involved in Aicardi-Goutieres syndrome implicate $S A M H D 1$ as regulator of the innate immune response. Nat Genet 41: 829-832.

Roberts R. 2015. A genetic basis for coronary artery disease. Trends Cardiovasc Med 25: 171-178.

Ruijs MW, van Andel RN, Oshima J, Madan K, Nieuwint AW, Aalfs CM. 2003. Atypical progeroid syndrome: An unknown helicase gene defect? Am J Med Genet A 116A: 295-299.

Saha B, Cypro A, Martin GM, Oshima J. 2014. Rapamycin decreases DNA damage accumulation and enhances cell growth of WRN-deficient human fibroblasts. Aging Cell 13: $573-575$

Savitsky K, Bar-Shira A, Gilad S, Rotman G, Ziv Y, Vanagaite L, Tagle DA, Smith S, Uziel T, Sfez S, et al. 1995. A single ataxia telangiectasia gene with a product similar to PI-3 kinase. Science 268: 1749-1753.

Schottker B, Saum KU, Jansen EH, Boffetta P, Trichopoulou A, Holleczek B, Dieffenbach AK, Brenner H. 2015. Oxidative stress markers and all-cause mortality at older age: A population-based cohort study. J Gerontol A Biol Sci Med Sci 70: 518-524.

Sebastiani P, Solovieff N, Dewan AT, Walsh KM, Puca A, Hartley SW, Melista E, Andersen S, Dworkis DA, Wilk JB, et al. 2012. Genetic signatures of exceptional longevity in humans. PLoS ONE 7: e29848.

Shalev SA, De Sandre-Giovannoli A, Shani AA, Levy N. 2007. An association of Hutchinson-Gilford progeria and malignancy. Am J Med Genet A 143A: 18211826.

Shimamoto A, Kagawa H, Zensho K, Sera Y, Kazuki Y, Osaki M, Oshimura M, Ishigaki Y, Hamasaki K, Kodama Y, et al. 2014. Reprogramming suppresses premature senescence phenotypes of Werner syndrome cells and maintains chromosomal stability over long-term culture. PLoS ONE 9: e112900.

Siitonen HA, Kopra O, Kaariainen H, Haravuori H, Winter RM, Saamanen AM, Peltonen L, Kestila M. 2003. Molecular defect of RAPADILINO syndrome expands the phenotype spectrum of RECQL diseases. Hum Mol Genet 12: 2837-2844.

Sobenin IA, Zhelankin AV, Sinyov VV, Bobryshev YV, Orekhov AN. 2014. Mitochondrial aging: Focus on mitochondrial DNA damage in atherosclerosis-A mini-review. Gerontology 61: 343-349.

Stephenson JB. 2008. Aicardi-Goutieres syndrome (AGS). Eur J Paediatr Neurol 12: 355-358. 
Suri S, Heise V, Trachtenberg AJ, Mackay CE. 2013. The forgotten APOE allele: A review of the evidence and suggested mechanisms for the protective effect of APOE varepsilon2. Neurosci Biobehav Rev 37: 2878-2886.

Suzuki H, Kurihara Y, Takeya M, Kamada N, Kataoka M, Jishage K, Ueda O, Sakaguchi H, Higashi T, Suzuki T, et al. 1997. A role for macrophage scavenger receptors in atherosclerosis and susceptibility to infection. Nature 386: $292-296$.

Takemoto M, Yamaga M, Furuichi Y, Yokote K. 2015. Astaxantin improved non-alcoholic fatty liver disease in Werner syndrome with diabetes. J Am Geristr Soc 63: 12711273.

Talaei F, van Praag VM, Henning RH. 2013. Hydrogen sulfide restores a normal morphological phenotype in Werner syndrome fibroblasts, attenuates oxidative damage and modulates mTOR pathway. Pharmacol Res 74: 34-44.

Tang Y, Le W. 2015. Differential Roles of M1 and M2 Microglia in neurodegenerative diseases. Mol Neurobiol doi: 10.1007/s12035-014-9070-5.

Thomas GS, Wann LS, Allam AH, Thompson RC, Michalik DE, Sutherland ML, Sutherland JD, Lombardi GP, Watson L, Cox SL, et al. 2014. Why did ancient people have atherosclerosis?: From autopsies to computed tomography to potential causes. Global Heart 9: 229-237.

Thompson D, Duedal S, Kirner J, McGuffog L, Last J, Reiman A, Byrd P, Taylor M, Easton DF. 2005. Cancer risks and mortality in heterozygous ATM mutation carriers. J Natl Cancer Inst 97: 813-822.

Valle L, Hernandez-Illan E, Bellido F, Aiza G, Castillejo A Castillejo MI, Navarro M, Segui N, Vargas G, Guarinos C, et al. 2014. New insights into POLE and POLD1 germline mutations in familial colorectal cancer and polyposis. Hum Mol Genet 23: 3506-3512.

Van Maldergem L, Siitonen HA, Jalkh N, Chouery E, De Roy M, Delague V, Muenke M, Jabs EW, Cai J, Wang LL, et al. 2006. Revisiting the craniosynostosis-radial ray hypoplasia association: Baller-Gerold syndrome caused by mutations in the RECQL4 gene. J Med Genet 43: 148152.

Vennos EM, James WD. 1995. Rothmund-Thomson syndrome. Dermatol Clin 13: 143-150.
Human Progeroid and Antigeroid Syndromes

Walden H, Deans AJ. 2014. The Fanconi anemia DNA repair pathway: Structural and functional insights into a complex disorder. Annu Rev Biophys 43: 257-278.

Wang JC, Bennett M. 2012. Aging and atherosclerosis: Mechanisms, functional consequences, and potential therapeutics for cellular senescence. Circ Res 111: 245259.

Wang LL, Levy ML, Lewis RA, Chintagumpala MM, Lev D, Rogers M, Plon SE. 2001. Clinical manifestations in a cohort of 41 Rothmund-Thomson syndrome patients. Am J Med Genet 102: 11-17.

Wang M, Jiang L, Monticone RE, Lakatta EG. 2014. Proinflammation: The key to arterial aging. Trends Endocrinol Metab 25: 72-79.

Weedon MN, Ellard S, Prindle MJ, Caswell R, Lango Allen H, Oram R, Godbole K, Yajnik CS, Sbraccia P, Novelli G, et al. 2013. An in-frame deletion at the polymerase active site of POLD1 causes a multisystem disorder with lipodystrophy. Nat Genet 45: 947-950.

Wei S, Soh SL, Qiu W, Yang W, Seah CJ, Guo J, Ong WY, Pang ZP, Han W. 2013. Seipin regulates excitatory synaptic transmission in cortical neurons. J Neurochem 124: 478-489.

Wilhelmsen L, Dellborg M, Welin L, Svardsudd K. 2015. Men born in 1913 followed to age 100 years. Scand Cardiovasc J 49: 45-48.

Williams GC. 1957. Pleiotropy, natural selection, and the evolution of senescence. Evolution 11: 398-411.

Willingale-Theune J, Schweiger M, Hirsch-Kauffmann M, Meek AE, Paulin-Levasseur M, Traub P. 1989. Ultrastructure of Fanconi anemia fibroblasts. J Cell Sci 93: 651-665.

Woods CG, Taylor AM. 1992. Ataxia telangiectasia in the British Isles: The clinical and laboratory features of 70 affected individuals. Q J Med 82: 169-179.

Wu L, Davies SL, Levitt NC, Hickson ID. 2001. Potential role for the BLM helicase in recombinational repair via a conserved interaction with RAD51. J Biol Chem 276: 19375-19381.

Xie Z, Jay KA, Smith DL, Zhang Y, Liu Z, Zheng J, Tian R, Li H, Blackburn EH. 2015. Early telomerase inactivation accelerates aging independently of telomere length. Cell 160: $928-939$. 


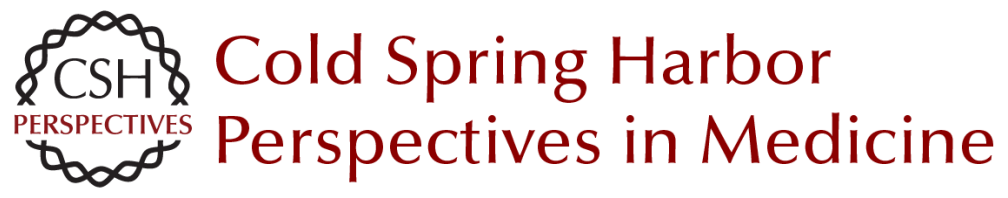

\section{How Research on Human Progeroid and Antigeroid Syndromes Can Contribute to the Longevity Dividend Initiative}

Fuki M. Hisama, Junko Oshima and George M. Martin

Cold Spring Harb Perspect Med 2016; doi: 10.1101/cshperspect.a025882 originally published online March 1, 2016

\section{Subject Collection Aging}

\section{Personalized Financial Planning Using Applied \\ Genetics \\ S. Jay Olshansky, Bradley Willcox, Kirk Ashburn, et al.}

Biological Restraints on Indefinite Survival Jan Vijg and Steven N. Austad

The Role of the National Institute on Aging in the Development of the Field of Geroscience Felipe Sierra and Ronald A. Kohanski

The Funding Channels of Geroscience Stephanie Lederman

\section{Evolutionary Approaches in Aging Research Melissa Emery Thompson}

Interventions for Human Frailty: Physical Activity as a Model Linda P. Fried

How Research on Human Progeroid and Antigeroid Syndromes Can Contribute to the Longevity Dividend Initiative

Fuki M. Hisama, Junko Oshima and George M. Martin

Articulating the Case for the Longevity Dividend S. Jay Olshansky

\section{Funding Life-Extension Research Mehmood Khan}
Influence of Aging Science on Global Wealth
Management Michael Hodin

International Gains to Achieving Healthy

Longevity Andrew Scott, Julian Ashwin, Martin Ellison, et al.

From Life Span to Health Span: Declaring

"Victory" in the Pursuit of Human Longevity S. Jay Olshansky

Crowdfunding and Crowdsourcing of Aging

Science

Keith Comito

Inhibition of the Mechanistic Target of Rapamycin (mTOR) - Rapamycin and Beyond

Dudley W. Lamming

The Emergence of Geroscience as an

Interdisciplinary Approach to the Enhancement of

Health Span and Life Span

Felipe Sierra

The Economic Promise of Delayed Aging Dana Goldman

For additional articles in this collection, see http://perspectivesinmedicine.cshlp.org/cgi/collection/ 